\title{
A comprehensive dataset of vegetation states, fluxes of matter and energy, weather, agricultural management, and soil properties from intensively monitored crop sites in western Germany
}

\author{
Tim G. Reichenau ${ }^{1}$, Wolfgang Korres ${ }^{1}$, Marius Schmidt ${ }^{2}$, Alexander Graf ${ }^{2}$, Gerhard Welp $^{3}$, \\ Nele Meyer ${ }^{3,4}$, Anja Stadler ${ }^{5}$, Cosimo Brogi ${ }^{2}$, and Karl Schneider ${ }^{1}$ \\ ${ }^{1}$ Institute of Geography, University of Cologne, Cologne, Germany \\ ${ }^{2}$ Institute of Bio- and Geosciences 3: Agrosphere (IBG-3), Jülich Research Centre, Jülich, Germany \\ ${ }^{3}$ Institute of Crop Science and Resource Conservation (INRES), Soil Science and Soil Ecology, \\ University of Bonn, Bonn, Germany \\ ${ }^{4}$ Department of Forest Sciences, University of Helsinki, Helsinki, Finland \\ ${ }^{5}$ Institute of Crop Science and Resource Conservation (INRES), Crop Science, \\ University of Bonn, Bonn, Germany \\ Correspondence: Tim Reichenau (tim.reichenau@uni-koeln.de)
}

Received: 11 October 2019 - Discussion started: 22 January 2020

Revised: 29 June 2020 - Accepted: 28 July 2020 - Published: 1 October 2020

\begin{abstract}
The development and validation of hydroecological land-surface models to simulate agricultural areas require extensive data on weather, soil properties, agricultural management, and vegetation states and fluxes. However, these comprehensive data are rarely available since measurement, quality control, documentation, and compilation of the different data types are costly in terms of time and money. Here, we present a comprehensive dataset, which was collected at four agricultural sites within the Rur catchment in western Germany in the framework of the Transregional Collaborative Research Centre 32 (TR32) "Patterns in Soil-Vegetation-Atmosphere Systems: Monitoring, Modeling and Data Assimilation". Vegetation-related data comprise fresh and dry biomass (green and brown, predominantly per organ), plant height, green and brown leaf area index, phenological development state, nitrogen and carbon content (overall $>17000$ entries), and masses of harvest residues and regrowth of vegetation after harvest or before planting of the main crop ( $>250$ entries). Vegetation data including LAI were collected in frequencies of 1 to 3 weeks in the years 2015 until 2017, mostly during overflights of the Sentinel 1 and Radarsat 2 satellites. In addition, fluxes of carbon, energy, and water (> 180000 half-hourly records) measured using the eddy covariance technique are included. Three flux time series have simultaneous data from two different heights. Data on agricultural management include sowing and harvest dates as well as information on cultivation, fertilization, and agrochemicals (27 management periods). The dataset also includes gap-filled weather data (> 200000 hourly records) and soil parameters (particle size distributions, carbon and nitrogen content; $>800$ records). These data can also be useful for development and validation of remote-sensing products. The dataset is hosted at the TR32 database (https://www.tr32db.uni-koeln.de/data.php?dataID=1889, last access: 29 September 2020) and has the DOI https://doi.org/10.5880/TR32DB.39 (Reichenau et al., 2020).
\end{abstract}




\section{Introduction}

System states and processes at the land surface are of major interest in the context of climate change and hydrological and biogeochemical research. In order to understand the processes in their spatial context and to provide information for larger areas, remote sensing and simulations are heavily applied methods. In this context, it is crucial to understand the fluxes mediated by the vegetation at the land surface. Dependencies of processes on vegetation states and properties and on environmental conditions are often investigated using models, while their spatial variability is inferred using remote-sensing techniques. In this context, well-documented and quality-controlled comprehensive field measurements of vegetation-related variables are essential for research tasks like model development, calibration, parameterization, and validation or as ground truth for remote-sensing products. These variables include biomass per organ differentiated between living (green) and senescent or diseased (brown) material, leaf area index (LAI), and the phenological state of the vegetation. For a simulation, additional information on site conditions such as vegetation composition, soil texture, weather, and, in the case of agroecosystem models, agricultural management is required (Kersebaum et al., 2015). However, there is a scarcity of such datasets (Jones et al., 2017). This is of special relevance since especially the crops grown and their properties differ between regions due to different soils and climate. Thus, detailed data on the named variables are required for different agricultural regions. With the publication of the data described in this article, we contribute a new coherent dataset on agroecosystems that includes all of the mentioned variables. The data were collected on conventionally managed fields cultivated by ordinary farmers working at the sites for many years. Thus, they represent conditions and usual practices representative of the intensively used agricultural region to the west of Cologne, in Germany. The dataset comprises data from four sites. It consists of almost 1500 records of vegetation parameters and more than 200000 entries of weather data complemented by 15 flux datasets (eddy covariance), management information for 27 management periods, and soil information for all four sites. In contrast to the ancillary data often available with flux data from the Fluxnet or Ameriflux databases, vegetation and soil data in this dataset are also available for other fields in the region, enabling extrapolation of field-scale results to the region. Since collecting field data is very time consuming and expensive, there are not many datasets of this size.

The data were collected in the Rur catchment, located at the Belgian-German-Dutch border, within the framework of the Transregional Collaborative Research Centre 32 (TR32; Vereecken et al., 2010; Simmer et al., 2015) "Patterns in Soil-Vegetation-Atmosphere Systems", funded by the German national science foundation (Deutsche Forschungsgemeinschaft, DFG). TR32 ran from 2007 until 2018. The project's main focus was on the combination of monitoring, modeling, and data assimilation to assess the role of patterns in soil-vegetation-atmosphere systems across scales. The monitoring efforts of TR32 were accompanied by the long-term research program TERENO (Terrestrial Environmental Observatories) of the Helmholtz Association (Bogena, 2016), which made additional instrumentation available for TR32. The data presented in this paper are highly valuable for many applications, such as those outlined in the publication list of TR32 (http://www.tr32.de, last access: 10 October 2019).

Here, we describe the observation sites and the structure of the dataset and provide information on the observation and measurement methods. Furthermore, we illustrate the quality assurance procedures. With the provision of this dataset, we want to document our measurement and quality control strategy and provide the scientific community with a comprehensive dataset for further applications.

\section{Observation sites}

All observation sites are located within the Rur catchment located at the Belgian-German-Dutch border (Fig. 1). The catchment is divided into a fertile loess plain ("Jülicher Börde" and "Zülpicher Börde") in the north and the low mountain range of the Eifel in the south. The fertile loess plain has a mean elevation of about $100 \mathrm{~m}$ a.s.l. The land use here is $47 \%$ arable land, with the main crops being winter wheat, sugar beet, and maize. The area has been inhabited since prehistoric times. Since there are confirmed signs of agriculture from 2000 years ago (Kalis, 1983), it can be assumed that the soil has been influenced by anthropogenic activities for several thousand years. The warm temperate midlatitude climate has an annual precipitation of about $700 \mathrm{~mm}$ and mean annual air temperature of about $10^{\circ} \mathrm{C}$. The major soils are Haplic Luvisols and Cumulic Anthrosols near the drainage lines, both with silty loamy textures. Soils close to the river Rur are Gleysols and Fluvisols with silty loamy and loamy sandy textures.

The low mountain range in the southern part of the catchment is characterized by a rolling topography. With a mean elevation of about $690 \mathrm{~m}$ a.s.l. and a mean annual precipitation of about $1400 \mathrm{~mm}$, it is dominated by forest and grassland. The major soils are Fluvisols, Gleysols (along the Rur and its tributaries), Eutric Cambisols, and Stagnic Gleysols with a silty loamy texture.

The location and numbering of the sites and fields are shown in Fig. 1. Terrain properties of each field are given in Table 1. Permission to take samples from the fields were given by the respective farmers.

\subsection{Selhausen}

The intensively used cropping site Selhausen is located in the east of the fertile loess plain $\left(50^{\circ} 52^{\prime} 00^{\prime \prime} \mathrm{N}, 6^{\circ} 27^{\prime} 01^{\prime \prime} \mathrm{E}\right)$. Crops are grown on gentle slopes $\left(<3^{\circ}\right)$. The altitude ranges 

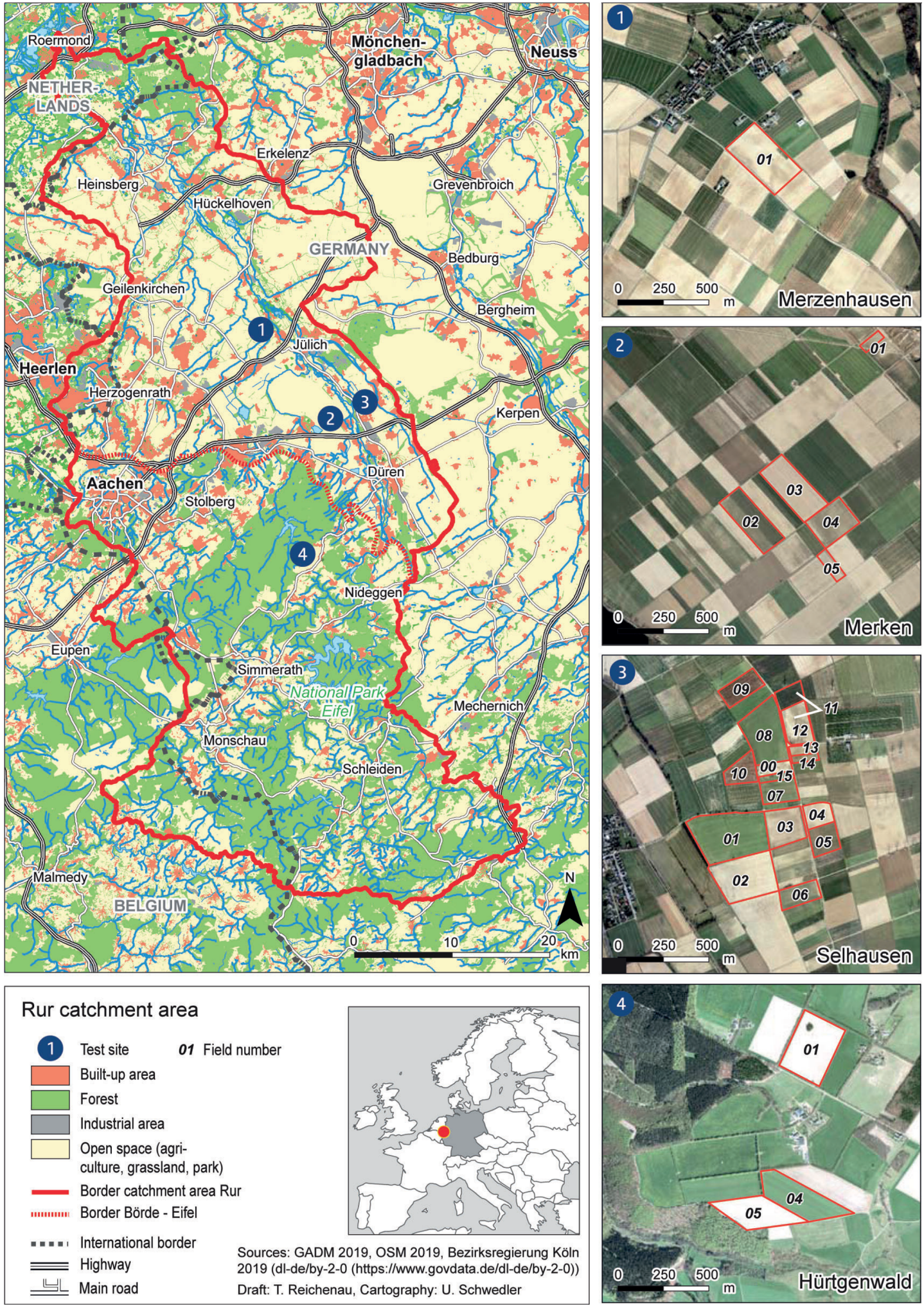

Figure 1. Left: locations of the observation sites in the Rur catchment in Germany. Right: locations of the fields at the observation sites with two-digit field IDs. At the Selhausen site (3), field 12 is a part of field 11. In the aerial photo of the Merken site (2), a part of field 01 is within the area of an open-pit mine. At the time of field measurements, the mine was about $2.5 \mathrm{~km}$ away from the field. Map data: GADM (https://gadm.org/license.html, last access: 1 October 2019), OpenStreetMap (Open Database License, ODbL, 1.0). Aerial photography: Land NRW (2019) Datenlizenz Deutschland - Namensnennung - Version 2.0 (https://www.govdata.de/dl-de/by-2-0, last access: 1 October 2019). Publisher's remark: please note that the above figure contains disputed territories. 
Table 1. Terrain properties of the fields. Coordinates are for centroids; projection is UTM 32N (WGS 1984).

\begin{tabular}{|c|c|c|c|c|c|c|}
\hline Site & Field & UTM N & UTM E & Elev. (m) & Area (ha) & Slope $\left(^{\circ}\right)$ \\
\hline \multirow[t]{16}{*}{ Selhausen (SE) } & F00 & 5638377 & 320584 & 105 & 1.2 & 1.5 \\
\hline & F01 & 5638008 & 320341 & 103 & 9.7 & 0.4 \\
\hline & F02 & 5637780 & 320428 & 104 & 7.4 & 0.4 \\
\hline & F03 & 5638056 & 320643 & 105 & 4.0 & 1.1 \\
\hline & F04 & 5638122 & 320826 & 109 & 1.9 & 0.7 \\
\hline & F05 & 5637987 & 320860 & 110 & 2.4 & 0.9 \\
\hline & F06 & 5637683 & 320723 & 107 & 2.4 & 1.5 \\
\hline & F07 & 5638251 & 320613 & 105 & 2.4 & 1.4 \\
\hline & F08 & 5638568 & 320538 & 104 & 6.5 & 1.4 \\
\hline & F09 & 5638818 & 320403 & 102 & 2.6 & 0.8 \\
\hline & F10 & 5638362 & 320408 & 103 & 2.2 & 0.7 \\
\hline & F11 & 5638671 & 320699 & 106 & 4.8 & 1.0 \\
\hline & $\mathrm{F} 12$ & 5638617 & 320713 & 107 & 3.1 & 0.7 \\
\hline & F13 & 5638478 & 320742 & 108 & 0.8 & 0.4 \\
\hline & $\mathrm{F} 14$ & 5638434 & 320754 & 109 & 0.6 & 0.5 \\
\hline & F15 & 5638329 & 320600 & 105 & 0.7 & 1.9 \\
\hline Merzenhausen (ME) & F01 & 5645502 & 310014 & 105 & 7.7 & 0.6 \\
\hline \multirow[t]{5}{*}{ Merken (MK) } & F01 & 5636968 & 317442 & 93 & 0.7 & 0.7 \\
\hline & F02 & 5635985 & 316781 & 108 & 5.3 & 0.6 \\
\hline & F03 & 5636161 & 317011 & 116 & 6.1 & 0.4 \\
\hline & F04 & 5635973 & 317223 & 114 & 4.3 & 0.4 \\
\hline & F05 & 5635738 & 317217 & 115 & 1.1 & 0.5 \\
\hline \multirow[t]{3}{*}{ Hürtgenwald (HW) } & F01 & 5622785 & 314460 & 360 & 8.4 & 2.4 \\
\hline & F04 & 5621961 & 314387 & 373 & 6.8 & 1.1 \\
\hline & F05 & 5621879 & 314156 & 374 & 5.7 & 2.6 \\
\hline
\end{tabular}

from 102 to $110 \mathrm{~m}$ a.s.l. According to the World Reference Base for Soil Resources (IUSS Working Group WRB, 2015), main soil reference groups are (gleyic) Cambisol and (gleyic) Luvisol. A westbound dip terrace slope cuts through the site with a NNW-SSE strike, separating areas with little gravel in the west (fields SE F01, F02, F10; Fig. 1) from areas with more gravel (fields SE F04, F05, F11-F14). Fields SE F03, F06-F09, and F15 show a high content of gravel in the east but low content in the west.

The climate exhibits an annual precipitation of $698 \mathrm{~mm}$ and a mean annual temperature of $9.9^{\circ} \mathrm{C}$ (average for 19612008, Juelich Kernf.-Anlage station of the German Meteorological Service, station ID 2474, about $5 \mathrm{~km}$ northwest).

The Selhausen site has been equipped with eddy covariance stations and meteorological sensors since 2007. Because it is the main agricultural observation site of TR32, numerous ancillary data from the site are available and have been presented in the literature (e.g., Busch et al., 2014; Hoffmeister et al., 2016; Korres et al., 2010; Prolingheuer et al., 2014; Schiedung et al., 2017; von Hebel et al., 2018; Bornemann et al., 2011; Ney and Graf, 2018; Schmidt et al., 2012). Beginning in 1895, historical maps document agricultural land use for field F01. Based on this information and the general findings that there has been agriculture in the region for several thousand years, it can be assumed that conversion of the fields into agricultural area does not have persisting effects on current states or processes.

\subsection{Merken}

The Merken site $\left(5^{\circ} 50^{\prime} 47^{\prime \prime} \mathrm{N}, 6^{\circ} 24^{\prime} 04^{\prime \prime} \mathrm{E}\right)$ is located $4.5 \mathrm{~km}$ to the southwest of Selhausen. Therefore, soil texture and meteorological conditions are similar. The area is dominated by agricultural fields. The elevation ranges from 107 to $115 \mathrm{~m}$ a.s.l., with slopes of less than $1^{\circ}$. The groundwater at the site is heavily influenced by a nearby open-pit mine. Additional information on the site is presented by Graf et al. (2011). From the farmers in the region it is known that the region was under agricultural use for at least 100 years. Based on the same information as for Selhausen, it can be assumed that conversion of the fields into agricultural area does not have persisting effects on current states or processes.

\subsection{Merzenhausen}

The Merzenhausen site $\left(50^{\circ} 55^{\prime} 47^{\prime \prime} \mathrm{N}, 6^{\circ} 17^{\prime} 46^{\prime \prime} \mathrm{E}\right)$ is located $13 \mathrm{~km}$ to the northwest of Selhausen at an altitude of $105 \mathrm{~m}$ a.s.l. and a slope of less than $1^{\circ}$. The area is dominated by agricultural fields. Mean annual temperature is $9.7^{\circ} \mathrm{C}$, and 
Table 2. Abbreviations for sites and land use types.

\begin{tabular}{ll}
\hline Site & Abbreviation \\
\hline Selhausen & SE \\
Merken & MK \\
Merzenhausen & ME \\
Hürtgenwald & HW \\
\hline Land use type & Abbreviation \\
\hline Catch crop & CC \\
Harvest residues* & HR \\
Maize & MA \\
Rapeseed & RA \\
Spelt & SP \\
Sugar beet & SB \\
Triticale & TC \\
Winter barley & WB \\
Winter wheat & WW \\
\hline
\end{tabular}

* Period before sowing and after harvest. This land use type was assigned independent of the actual presence of residues on the field.

mean annual precipitation is $750 \mathrm{~mm}$ (Schulz, 2004). The soil at the sampling location is described as an Orthic or Haplic Luvisol (Heitmann-Weber et al., 1994; Schulz, 2004). We have no detailed information on the land use history of this field. However, since tombs from the Bronze Age have been found close to the site, concerning effects of land use conversion, the same assumptions as for Selhausen and Merken apply.

\subsection{Hürtgenwald}

The observation site Hürtgenwald $\left(50^{\circ} 43^{\prime} 26^{\prime \prime} \mathrm{N}, 6^{\circ} 22^{\prime} 8^{\prime \prime} \mathrm{E}\right)$ is located in the northern part of the low mountain range of the Eifel. The altitude ranges from 360 to $375 \mathrm{~m}$ a.s.l., with varying slopes. The hilly terrain is dominated by forest, pasture, and arable land. The reference soil groups are described as Cambisol or Arenosol (Geological Survey of North RhineWestphalia). According to long-term private meteorological measurements (https://www.huertgenwaldwetter.de/, last access: 19 July 2019), the annual precipitation is $946 \mathrm{~mm}$ (2000-2018), and the annual mean temperature is $9.4^{\circ} \mathrm{C}$ (1998-2018). For the site Hürtgenwald, it is known that since the end of World War II, there has not been any forest on the fields. Earlier, they might have been used for forestry. At least since 1953, the fields were used agriculturally, alternating between arable land and grassland.

\section{Conventions and dataset structure}

The vegetation data are structured in management periods, which are defined by a combination of the observation site, the field, the crop, and the year. A dataset identifier is assigned to each management period, such as, for example,

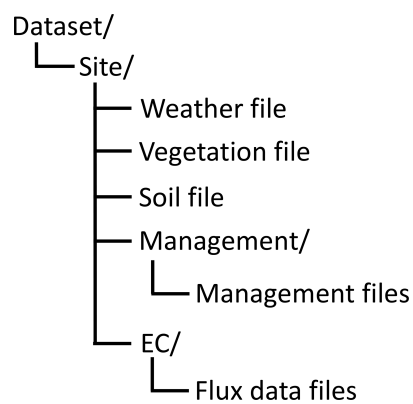

Figure 2. Folder structure of the dataset. A slash (“/”) denotes a directory.

"SEF05WW15", which describes a management period at the site Selhausen (SE) on field 5 (F05) where winter wheat (WW) was harvested in the year 2015 (15). A management period can be either the growing period of a crop or the between-cropping period, where the field is fallow. The fallow period can be discontinuous and refers to the periods before planting and after the harvesting of a crop.

Data on fluxes and agricultural management can be matched to the management periods by the site, the field, and the year. Meteorological data are given per site. Soil parameters are available for several points at a site. All measurement locations are identified by their positions and are assigned to fields. Fields are defined by field boundaries with a specific land use and homogeneous agricultural management. In the dataset and throughout this text, sites and land use types are abbreviated as shown in Table 2, while the field numbering is shown in Fig. 1.

Additional conventions include the following:

- For a crop, the given year is the year when the crop was harvested.

- Time and date are in UTC.

- Coordinates are given in UTM (Zone 32N, WGS 1984).

The dataset (Reichenau et al., 2020) is provided as a zip file containing text files in a separate folder for each site as shown in Fig. 2. Details on the data format are described below. An overview of management periods and available data is presented in Table 3 .

\subsection{Missing data}

Missing (or unknown) data are denoted by the symbol NA throughout the dataset. There are three main causes of missing data.

1. Since the data described in this document are mostly results from field measurements, some numbers are missing due to instrument failure or quality issues (see sections on quality assurance). For data on agricultural management, data availability depends on the willingness of the farmers to report their activities. 
Table 3. Data availability for vegetation data, fluxes, and management data ("X" data available, "_" no data available). For an explanation of vegetation data categories, refer to Sect. 4. For crops, the year refers to harvest. Concerning vegetation data, the number of points gives the maximum number of points in the field measured on the same date. In the event of harvest residues, green sprouts, and other biomass, data are only marked available if at least one value unequal to zero is available.

\begin{tabular}{|c|c|c|c|c|c|c|c|c|c|c|c|c|c|c|c|c|c|c|c|c|c|c|c|}
\hline \multicolumn{7}{|c|}{ Dataset } & \multirow[b]{2}{*}{ 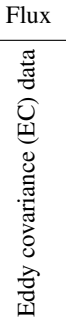 } & \multicolumn{6}{|c|}{ Management } & \multicolumn{10}{|c|}{ Vegetation } \\
\hline Identifier & $\stackrel{\frac{\Xi}{二}}{\Delta}$ & $\frac{\bar{\sigma}}{\frac{D}{2}}$ & రి & 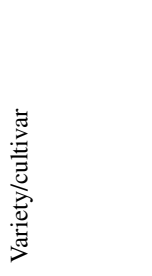 & ‡ँ & 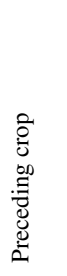 & & 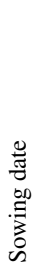 & 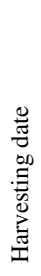 & 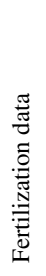 & 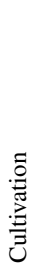 & 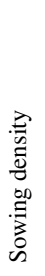 & 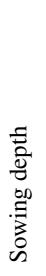 & 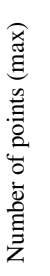 & 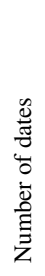 & 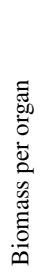 & 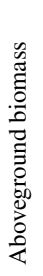 & $\underset{\triangleleft}{\longleftarrow}$ & 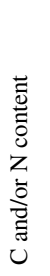 & 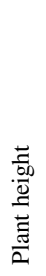 & 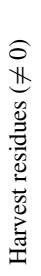 & $\begin{array}{l}\hat{0} \\
\mathbb{H} \\
0 \\
0 \\
0 \\
0 \\
0 \\
\tilde{0} \\
0 \\
0\end{array}$ & 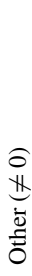 \\
\hline SEF08WW08 & SE & F08 & WW & Raspail & 2008 & SB & $\mathrm{X}$ & $X$ & $X$ & $X$ & - & - & - & 3 & 10 & $X$ & - & $X$ & $X$ & $X$ & - & - & $\mathrm{X}$ \\
\hline SEF01SB08 & SE & F01 & SB & - & 2008 & - & - & $\mathrm{X}$ & - & $\mathrm{X}$ & - & $\mathrm{X}$ & - & 3 & 8 & $X$ & - & $\mathrm{X}$ & $X$ & $X$ & - & - & - \\
\hline SEF14MA08 & SE & F14 & MA & - & 2008 & - & - & $X$ & - & $X$ & - & - & - & 3 & 8 & $X$ & - & $X$ & $X$ & $\mathrm{X}$ & - & - & $\mathrm{X}$ \\
\hline SEF11RA08 & SE & F11 & RA & - & 2008 & WB & - & $\mathrm{X}$ & - & $\mathrm{X}$ & - & $X$ & - & 3 & 9 & $\mathrm{X}$ & - & $\mathrm{X}$ & $\mathrm{X}$ & $X$ & - & - & $\mathrm{X}$ \\
\hline SEF08WW09 & SE & F08 & WW & Raspail & 2009 & WW & $X$ & $X$ & $X$ & $X$ & $X$ & $X$ & - & 3 & 14 & $X$ & - & $X$ & $X$ & $X$ & - & - & - \\
\hline SEF07SB09 & SE & F07 & SB & Pauletta & 2009 & - & - & $\mathrm{X}$ & $X$ & $\mathrm{X}$ & $\mathrm{X}$ & $X$ & $\mathrm{X}$ & 3 & 11 & $X$ & - & $X$ & $X$ & $X$ & - & - & - \\
\hline SEF10MA09 & SE & F10 & MA & Agro Lux & 2009 & - & - & $\mathrm{X}$ & $\mathrm{X}$ & $\mathrm{X}$ & $\mathrm{X}$ & $X$ & $\mathrm{X}$ & 3 & 8 & $X$ & - & $\mathrm{X}$ & $X$ & $X$ & - & - & - \\
\hline SEF13RA09 & SE & F13 & RA & - & 2009 & - & - & $\mathrm{X}$ & $X$ & $\mathrm{X}$ & $\mathrm{X}$ & - & $\mathrm{X}$ & 3 & 13 & $X$ & - & $X$ & $X$ & $X$ & - & - & $\mathrm{X}$ \\
\hline SEF15WB09 & SE & F15 & WB & Laverda & 2009 & - & - & - & - & - & - & - & - & 3 & 8 & $\mathrm{X}$ & - & $\mathrm{X}$ & $\mathrm{X}$ & $X$ & - & - & - \\
\hline MKF05MA09 & MK & F05 & MA & Ronaldinho & 2009 & - & - & $\mathrm{X}$ & $\mathrm{X}$ & $\mathrm{X}$ & $\mathrm{X}$ & - & - & 3 & 7 & $X$ & - & $\mathrm{X}$ & $X$ & $X$ & - & - & - \\
\hline MKF01RA09 & MK & F01 & $\mathrm{RA}$ & NK-Fair & 2009 & - & - & $\mathrm{X}$ & $X$ & $\mathrm{X}$ & $\mathrm{X}$ & $\mathrm{X}$ & $\mathrm{X}$ & 3 & 9 & $X$ & - & $\mathrm{X}$ & $X$ & $\mathrm{X}$ & - & - & - \\
\hline MKF04SB09 & MK & F04 & SB & Beretta KWS & 2009 & - & $\mathrm{X}^{*}$ & $\mathrm{X}$ & $\mathrm{X}$ & $X$ & $X$ & $X$ & $X$ & 3 & 10 & $X$ & - & $X$ & $X$ & $X$ & - & - & - \\
\hline MKF03WB09 & MK & F03 & WB & Fridericus & 2009 & - & $\mathrm{X}^{*}$ & $\mathrm{X}$ & $\mathrm{X}$ & $\mathrm{X}$ & - & $\mathrm{X}$ & $\mathrm{X}$ & 3 & 8 & $\mathrm{X}$ & - & $\mathrm{X}$ & $\mathrm{X}$ & $\mathrm{X}$ & - & - & - \\
\hline MKF02WW09 & MK & F02 & WW & Hattrick & 2009 & - & $\mathrm{X}^{*}$ & $X$ & $\mathrm{X}$ & $\mathrm{X}$ & $\mathrm{X}$ & - & $\mathrm{X}$ & 3 & 10 & $\mathrm{X}$ & - & $\mathrm{X}$ & $\mathrm{X}$ & $\mathrm{X}$ & - & - & - \\
\hline SEF07WW10 & SE & F07 & WW & - & 2010 & SB & - & - & - & - & - & - & - & 6 & 10 & $\mathrm{X}$ & - & $\mathrm{X}$ & $\mathrm{X}$ & $X$ & - & - & - \\
\hline SEF08SB10 & SE & F08 & SB & Supero & 2010 & WW & - & $\mathrm{X}$ & $\mathrm{X}$ & $\mathrm{X}$ & $\mathrm{X}$ & - & $\mathrm{X}$ & 7 & 12 & $\mathrm{X}$ & - & $\mathrm{X}$ & $\mathrm{X}$ & $\mathrm{X}$ & - & - & - \\
\hline SEF09MA10 & SE & F09 & MA & - & 2010 & - & - & - & - & - & - & - & - & 3 & 1 & $\mathrm{X}$ & - & $\mathrm{X}$ & - & $\mathrm{X}$ & - & - & - \\
\hline SEF12RA10 & SE & $\mathrm{F} 12$ & RA & - & 2010 & - & - & - & - & - & - & - & - & 5 & 8 & $X$ & - & $X$ & $X$ & $X$ & - & - & - \\
\hline SEF01WB10 & $\mathrm{SE}$ & F01 & WB & - & 2010 & - & - & - & - & - & - & - & - & 5 & 8 & $X$ & - & $X$ & - & $X$ & - & - & - \\
\hline MKF04WW10 & MK & F04 & WW & - & 2010 & SB & - & - & - & - & - & - & - & 3 & 2 & $X$ & - & $X$ & - & $X$ & - & - & - \\
\hline MKF02WB10 & MK & F02 & WB & - & 2010 & WW & - & - & - & - & - & - & - & 3 & 2 & $X$ & - & $\mathrm{X}$ & - & $\mathrm{X}$ & - & - & - \\
\hline MEF01HR11 & $\mathrm{ME}$ & F01 & $\mathrm{HR}$ & - & 2011 & - & $\mathrm{X}$ & - & - & - & - & - & - & 12 & 1 & - & - & - & $\mathrm{X}$ & - & $X$ & - & - \\
\hline MEF01WW11 & ME & F01 & WW & Potenzial & 2011 & SB & $\mathrm{X}$ & $\mathrm{X}$ & $\mathrm{X}$ & $\mathrm{X}$ & - & $\mathrm{X}$ & $\mathrm{X}$ & 12 & 10 & $\mathrm{X}$ & - & $\mathrm{X}$ & $\mathrm{X}$ & $\mathrm{X}$ & - & - & - \\
\hline MEF01HR12 & ME & F01 & $\mathrm{HR}$ & - & 2012 & - & $\mathrm{X}$ & - & - & - & - & - & - & 12 & 1 & - & - & - & - & - & $\mathrm{X}$ & - & - \\
\hline MEF01WW12 & $\mathrm{ME}$ & F01 & WW & Tobak & 2012 & WW & $X$ & $\mathrm{X}$ & $X$ & $\mathrm{X}$ & - & $X$ & $\mathrm{X}$ & 12 & 12 & $\mathrm{X}$ & - & $\mathrm{X}$ & $\mathrm{X}$ & $\mathrm{X}$ & - & - & - \\
\hline SEF04WW13 & $\mathrm{SE}$ & F04 & WW & - & 2013 & - & - & - & - & - & - & - & - & 6 & 10 & $X$ & - & $\mathrm{X}$ & $X$ & $\mathrm{X}$ & - & - & - \\
\hline SEF01HR15 & SE & F01 & HR & - & 2015 & - & $X$ & - & - & - & - & - & - & 3 & 3 & - & - & - & - & $X$ & $X$ & - & - \\
\hline SEF01WW15 & SE & F01 & WW & Premio & 2015 & - & $X$ & $X$ & $X$ & $X$ & - & - & - & 3 & 6 & $X$ & - & $X$ & - & $X$ & - & - & - \\
\hline SEF03HR15 & SE & F03 & HR & - & 2015 & - & - & - & - & - & - & - & - & 3 & 5 & - & - & - & - & - & $X$ & $\mathrm{X}$ & $\mathrm{X}$ \\
\hline SEF03WW15 & SE & F03 & WW & - & 2015 & - & - & $\mathrm{X}$ & $\mathrm{X}$ & $\mathrm{X}$ & - & $\mathrm{X}$ & $\mathrm{X}$ & 3 & 6 & $\mathrm{X}$ & $\mathrm{X}$ & $\mathrm{X}$ & - & $\mathrm{X}$ & - & - & - \\
\hline SEF02SB15 & SE & F02 & SB & - & 2015 & - & - & - & - & - & - & - & - & 3 & 7 & $\mathrm{X}$ & - & $\mathrm{X}$ & - & $X$ & - & - & $\mathrm{X}$ \\
\hline SEF04HR15 & SE & F04 & HR & - & 2015 & - & - & - & - & - & - & - & - & 3 & 5 & - & - & - & - & - & $X$ & $\mathrm{X}$ & $\mathrm{X}$ \\
\hline SEF04SP15 & SE & F04 & $\mathrm{SP}$ & - & 2015 & WW & - & - & - & - & - & - & - & 3 & 4 & $\mathrm{X}$ & - & $\mathrm{X}$ & - & $\mathrm{X}$ & - & - & - \\
\hline SEF05HR15 & SE & F05 & HR & - & 2015 & - & - & - & - & - & - & - & - & 3 & 3 & - & - & - & - & - & $X$ & $X$ & - \\
\hline SEF05WW15 & SE & F05 & WW & - & 2015 & - & - & - & - & - & - & - & - & 3 & 4 & $\mathrm{X}$ & $X$ & $\mathrm{X}$ & - & $\mathrm{X}$ & - & - & - \\
\hline HWF01HR15 & HW & F01 & $\mathrm{HR}$ & - & 2015 & - & - & - & - & - & - & - & - & 3 & 2 & - & - & - & - & $X$ & $X$ & - & - \\
\hline HWF01MA15 & HW & F01 & MA & Silage maize & 2015 & - & - & $\mathrm{X}$ & $\mathrm{X}$ & $\mathrm{X}$ & $\mathrm{X}$ & $\mathrm{X}$ & $\mathrm{X}$ & 3 & 7 & $\mathrm{X}$ & - & $\mathrm{X}$ & - & $\mathrm{X}$ & - & - & $\mathrm{X}$ \\
\hline HWF04HR15 & HW & F04 & HR & - & 2015 & - & - & - & - & - & - & - & - & 0 & 1 & - & - & - & - & - & - & - & - \\
\hline HWF04TC15 & HW & F04 & $\mathrm{TC}$ & Winter TC & 2015 & - & - & $X$ & $X$ & $X$ & $X$ & - & $X$ & 3 & 3 & $X$ & $X$ & $X$ & - & $X$ & - & - & $\mathrm{X}$ \\
\hline SEF01WB16 & SE & F01 & WB & - & 2016 & WW & $X$ & $X$ & $\mathrm{X}$ & $\mathrm{X}$ & $\mathrm{X}$ & - & - & 3 & 7 & $\mathrm{X}$ & - & $\mathrm{X}$ & - & $X$ & - & - & - \\
\hline SEF01HR16 & SE & F01 & HR & - & 2016 & - & $X$ & - & - & - & - & - & - & 3 & 3 & - & - & - & - & $X$ & $X$ & $X$ & - \\
\hline SEF01CC16 & SE & F01 & $\mathrm{CC}$ & - & 2016 & WB & $X$ & $X$ & $X$ & $X$ & $X$ & - & - & 3 & 2 & - & $X$ & - & - & $X$ & - & - & - \\
\hline SEF03HR16 & SE & F03 & HR & - & 2016 & WW & - & - & - & - & - & - & - & 3 & 3 & - & - & - & - & - & $\mathrm{X}$ & - & - \\
\hline SEF03SB16 & SE & F03 & SB & - & 2016 & WW & - & - & - & - & - & - & - & 3 & 7 & $\mathrm{X}$ & - & $\mathrm{X}$ & - & $\mathrm{X}$ & - & - & - \\
\hline SEF04HR16 & SE & F04 & HR & - & 2016 & - & - & - & - & - & - & - & - & 0 & 2 & - & - & - & - & - & - & - & - \\
\hline SEF04SB16 & SE & F04 & SB & Kleist & 2016 & SP & - & $X$ & - & $X$ & $X$ & $X$ & $X$ & 3 & 7 & $X$ & - & $\mathrm{X}$ & - & $X$ & - & - & - \\
\hline SEF05HR16 & SE & F05 & $\mathrm{HR}$ & - & 2016 & WW & - & - & - & - & - & - & - & 3 & 3 & - & - & - & - & $\mathrm{X}$ & $\mathrm{X}$ & - & - \\
\hline SEF05WW16 & SE & F05 & WW & - & 2016 & WW & - & - & - & - & - & - & - & 3 & 7 & $X$ & $X$ & $X$ & - & $X$ & - & - & - \\
\hline SEF06HR16 & SE & F06 & HR & - & 2016 & - & - & - & - & - & - & - & - & 4 & 2 & - & - & - & - & $X$ & $X$ & - & - \\
\hline SEF06WB16 & SE & F06 & WB & - & 2016 & - & - & - & - & - & - & - & - & 4 & 7 & $X$ & - & $X$ & - & $X$ & - & - & - \\
\hline HWF01HR16 & HW & F01 & HR & - & 2016 & - & - & - & - & - & - & - & - & 3 & 4 & - & - & - & - & $X$ & $X$ & - & - \\
\hline HWF01MA16 & HW & F01 & MA & - & 2016 & MA & - & - & $\mathrm{X}$ & $\mathrm{X}$ & $\mathrm{X}$ & $X$ & $\mathrm{X}$ & 3 & 4 & $\mathrm{X}$ & - & $\mathrm{X}$ & - & $X$ & - & - & $\mathrm{X}$ \\
\hline HWF05HR16 & HW & F05 & HR & - & 2016 & - & - & - & - & - & - & - & - & 0 & 1 & - & - & - & - & $X$ & - & - & - \\
\hline HWF05TC16 & HW & F05 & $\mathrm{TC}$ & - & 2016 & - & - & $X$ & $X$ & - & $X$ & - & $X$ & 3 & 4 & $X$ & $X$ & $X$ & - & $X$ & $X$ & - & - \\
\hline SEF06WB17 & SE & F06 & WB & - & 2017 & WB & - & - & - & - & - & - & - & 6 & 1 & $X$ & - & $X$ & - & $X$ & - & - & - \\
\hline MEF01HR17 & $\mathrm{ME}$ & F01 & $\mathrm{HR}$ & - & 2017 & - & $X$ & - & - & - & - & - & - & 3 & 1 & - & - & - & - & $X$ & - & - & - \\
\hline MEF01WW17 & ME & F01 & WW & - & 2017 & - & $X$ & $\mathrm{X}$ & - & - & $\mathrm{X}$ & - & - & 3 & 7 & $\mathrm{X}$ & - & $X$ & - & $\mathrm{X}$ & - & - & $\mathrm{X}$ \\
\hline
\end{tabular}


2. Consistency between sites and management periods: if a certain measured variable is available for one site, the variable is also listed in the respective data table of the other sites to keep the data format consistent. If there are no data for the respective variable at a site, all data points in that column are marked NA.

3. Consistency with predefined file formats: for flux data, we used pre-existing file formats, which define columns for variables that were not measured in our case. This causes columns totally filled with NA.

\section{Vegetation data}

\subsection{Data source and methods}

The vegetation data contain information on fresh and dry biomass, development state, growth height, canopy density, row spacing, and tissue nitrogen and carbon content. Data on biomass are either differentiated by organ (brown and green leaves and stems, respectively, and fruit) or undifferentiated as overall aboveground biomass (named "biomass_undiff"). Furthermore, data on the undifferentiated biomass categories "harvest residues" or "green sprouts" may be included in a record. Harvest residues are understood as the aboveground residues after harvesting, which can be material lying on the ground or stubble left standing. Green sprouts are defined as plants growing between the harvest residues or on an otherwise fallow field. This can be weeds or regrowing crops (especially cereals). In addition, an undifferentiated biomass category named "biomass_other" may contain biomass of roots, weeds, or the like (specified in the database column "other_descr").

Vegetation data were collected from 2007 to 2017 at different sites and fields (see Table 3). Biomass and leaf area from at least three points in the field were determined destructively. For row crops, the number of plants within a certain distance of the row was also determined. For cereals, plants were taken from 40 or $50 \mathrm{~cm}$ in three different rows. Triticale in Hürtgenwald was not sown in rows. Thus, plants from an area of at least $40 \mathrm{~cm} \times 40 \mathrm{~cm}$ were collected. For crops with large individual plants like maize or sugar beet and for rapeseed, the number of plants per square meter was determined from the row spacing and the number of plants per meter. At least three individual plants were collected at each point. In the field, canopy height and row spacing were measured at each sampling location before cutting the plants. The position in the field was determined using a GPS device. In addition, the phenological development state of the crop was assessed using the BBCH scale (Meier et al., 2009).

After being transported to the lab in airtight bags, the fresh weight (FW) of the plant sample was determined. An aliquot of $150 \mathrm{~g}$ or at least one individual plant was further analyzed. In the event of a per-organ analysis, the sample was separated into fruit (understood as the harvested organ like ear, beet, etc.), green or brown stems (shoots), and green or brown leaves. A leaf or stem was classified as brown if $50 \%$ of its surface was not green. A functional definition of a leaf was applied for cereal leaves where only the leaf blade was considered as a leaf, while the leaf sheath was assigned to the stem. Blossoms were defined as fruit. For Maize, the male blossoms on top of the plant were assigned to the stem, and only the female blossoms and the maize cobs that evolve from them were defined as fruit.

The leaf area was determined using either a LI-3000A area meter with a LI-3050A belt conveyer (LI-COR Biosciences, Lincoln, NE, USA) or a flatbed scanner (Epson GT-15000, Seiko Epson Corp., Suwa, Japan) together with the public domain image analysis software ImageJ (https: //imagej.nih.gov/ij/, last access: 10 October 2019). In a comparison using the same samples, both methods were shown to give equivalent results. Before determining the dry weight (DW), samples were dried in a drying oven at $105^{\circ} \mathrm{C}$ for at least $3 \mathrm{~d}$. For some samples, aliquots of the dried plant material were homogenized in a mortar and subsequently ground in a ball mill to determine the total content of carbon and nitrogen with an elemental analyzer (CNS elemental analyzer Vario EL, Elementar Analysensysteme GmbH, Hanau, Germany). This also includes nine records of $\mathrm{C}$ and $\mathrm{N}$ content of harvest residues. Upscaling to a square meter of the field was accomplished in a two-step process: from the weighed aliquot to the sample collected in the field and from the sample to a square meter of the field based on the harvested area or the plant density (for MA, SB, RA). Dry weight and LAI were scaled up in proportion to fresh weight.

Additional information includes the following:

- The frequency of data collection ranges from 1 to 3 weeks. The number of measurements in each management period can be seen in Table 3 .

- In the years 2015 until 2017, vegetation data were sampled on overflight days of a radar satellite (Sentinel 1, Radarsat 2).

- Per-organ data of crops for fields at a particular site without organ-specific measurements may be estimated from organ-specific biomass measurements for fields of the same crop on this site assuming equal proportions of the total aboveground biomass. The validity of this approach depends on the similarity of soil and management conditions.

- Prior to 2011, harvest residues and green sprouts were not sampled in the field. Therefore, these entries are always set undefined (NA) in the years 2007 until 2010. LAI is undefined instead of zero where no LAI was reported in the field protocol.

- During the management periods HWF04HR15 and SEF04HR16, the fields were fallow. Therefore, all vegetation data are zero. These management periods and 


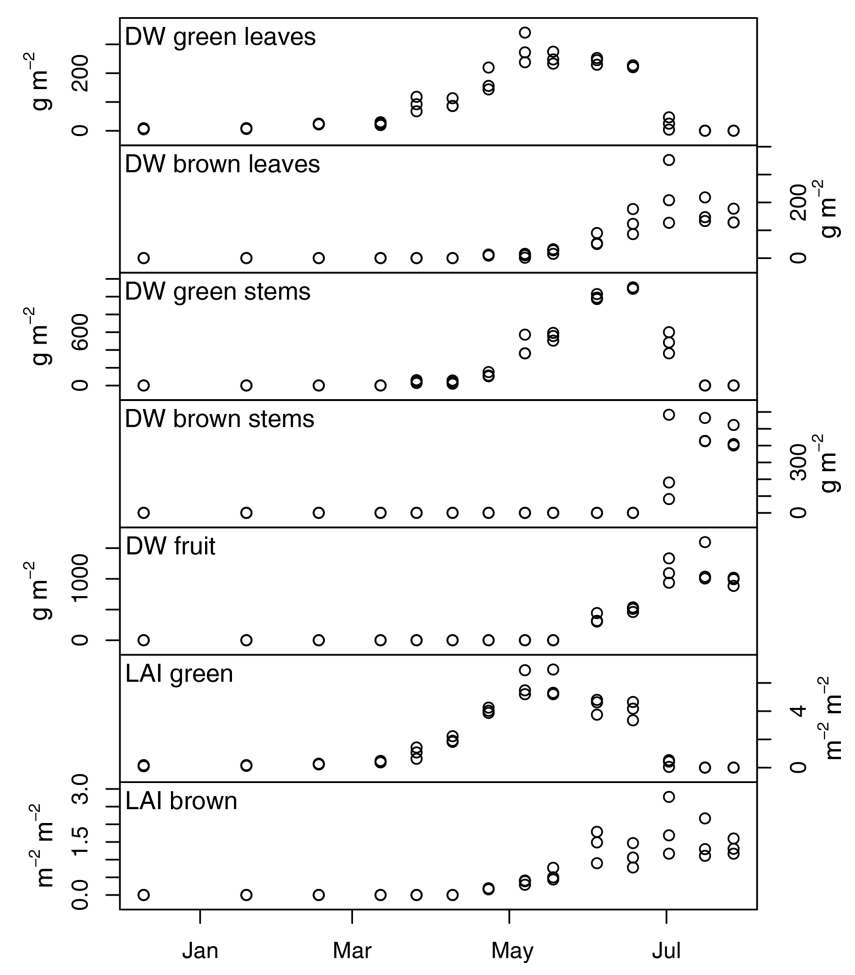

Figure 3. Dry weight (DW) and leaf area index (LAI) of winter wheat on field F08 at the Selhausen site in 2009. Dataset identifier is SEF08WW09.

other entries containing only zeroes are included in the dataset to document dates where the field observations showed no biomass on the field. Explicitly distinguishing no biomass from undefined or no data (NA) provides important information for calibration or validation of remote-sensing products.

Figure 3 exemplarily shows dry weights and leaf area index of winter wheat from field F08 at the Selhausen site in 2009 (dataset identifier SEF08WW09). For this management period, three samples per field were collected at each of the 14 dates beginning in December 2008. The last samples were taken on 27 July 2009, 1 d before harvest on 28 July 2009. The graphs nicely show that the exponential growth phase in April comes along with higher variability between the points in the field in terms of green biomass and LAI. With the beginning of senescence in late May, brown biomass and LAI emerge, showing even higher variability. This is a result of small-scale spatial variability of soil and vegetation properties and terrain under field conditions, which is important information for model evaluation.

Using the data in remote-sensing applications often results in scale problems. Since only small patches of $40 \mathrm{~cm} \times 40 \mathrm{~cm}$ or three rows of $50 \mathrm{~cm}$ in length could be harvested, there is a scale gap between the ground truth and the pixels of a remote-sensing scene, which often have edge lengths of more than $100 \mathrm{~m}$. A possible way to bridge this gap can be high-resolution remote-sensing products. For the estimation of LAI, Brogi et al. (2020) calibrated the algorithm of Ali et al. (2015) based on the Normalized Difference Vegetation Index (NDVI) derived from $5 \mathrm{~m}$ resolution RapidEye level $3 \mathrm{~A}$ data. LAI data from the dataset described here were used as ground truth. Reichenau et al. (2016) showed that realistic statistical distributions of LAI over a larger area could even be derived without calibration. However, in that case ground truth is required to prove this. The resulting $5 \mathrm{~m}$ resolution LAI data can then be spatially aggregated to bridge the gap to lower-resolution datasets.

Examples of the application of the vegetation data can be found in Ahrends et al. (2014), Brogi et al. (2020), Korres et al. (2013), Ney and Graf (2018), Reichenau et al. (2016), and Schmidt et al. (2012).

\subsection{Quality assurance}

The first step of the quality assurance procedure for the vegetation data was a rigorous documentation of the measuring process. In addition to written documentation on any phenomena, which might have affected the measurement (in the field and in the lab), a photographic documentation of the samples in the field and in the lab enables a visual inspection and provides independent evidence in case of any doubts. Transcribing the analog protocols into a spreadsheet-based (MS Excel) digital field protocol provides a first test of data consistency. Possible errors, inconsistencies, or incomplete data are reported automatically, and the personnel entering the data are prompted to check the entries. Transcribing the data from the analog protocol to a digital dataset is done as soon as possible to be able to trace possible errors. Keeping analog field protocols provides a double documentation of the valuable measurements and observations. In the second step, tests on consistency and plausibility were applied, which ensure that

- coordinates are in UTM projection, and timestamps are in UTC;

- naming of crops, sites, and points follows conventions;

- values are in plausible ranges;

- missing values are set to unknown (NA);

- the right upscaling method is set for a crop throughout a management period;

- there are no duplicate coordinates for points in a field at the same date.

A third step comprises statistical tests, which result in a quality flag for each value in the dataset (see below). These tests were applied using an R script (R Core Team, 2017), which reads from the digital field protocols, assigns the quality flags, and finally writes the files provided in the dataset. 


\subsubsection{Quality flags}

The quality flags can take the values 1 to 5 :

1. high quality (all tests could be applied, and no problems were identified; no problems were identified in the field)

2. good quality (a test could not be applied; information is missing to ensure high quality)

3. unusual water content (a specific flag concerning the measured water content of the sample, which may hint at problems with biomass measurements)

4. suspicious (a test or a documented issue in the protocol showed possible problems)

5. low quality (a value is known to have problems but is of interest as evidence of the real conditions, e.g., root biomass)

The flags were set based on the criteria explained below. After evaluation of all tests, the flag with the highest value was assigned. Obviously erroneous data were removed from the dataset. There are no flags for the carbon and nitrogen content of the plant tissue.

\subsubsection{General flagging}

Weight measurements below $1 \mathrm{~g}$ were generally flagged as good quality (2) instead of high quality (1) as it is quite likely to lose material from samples, which will have a larger relative effect than for high biomass. All harvest residues are generally flagged as suspicious (4). This is due to the fact that precise collection of only the aboveground material is rather difficult and error-prone. It is even more difficult to extract the belowground biomass. Therefore, root biomass (given as "biomass_other") is generally flagged as low quality (5).

\subsubsection{Loss of material}

In most cases, a sample from the field had to be differentiated into fractions (organs, harvest residues, green sprouts). For larger samples, only a part (aliquot) was analyzed in the lab (see Sect. 4.1). For organ-specific analysis, this aliquot is the sum of all organs. In the event of undifferentiated biomass, the aliquot is the sum of the biomass categories biomass_undiff, harvest_residues, green_sprouts, and biomass_other. During the process of sample partitioning some material might get lost, causing a difference between the aliquot and the sum of its components (median $1 \%$ ). Differences of up to $5 \%$ were accepted independent of their sign. Larger differences result in higher values of the quality flag (Table 4). Higher flags are set if the sum of their components exceeded the aliquot because this cannot be explained by losing material.

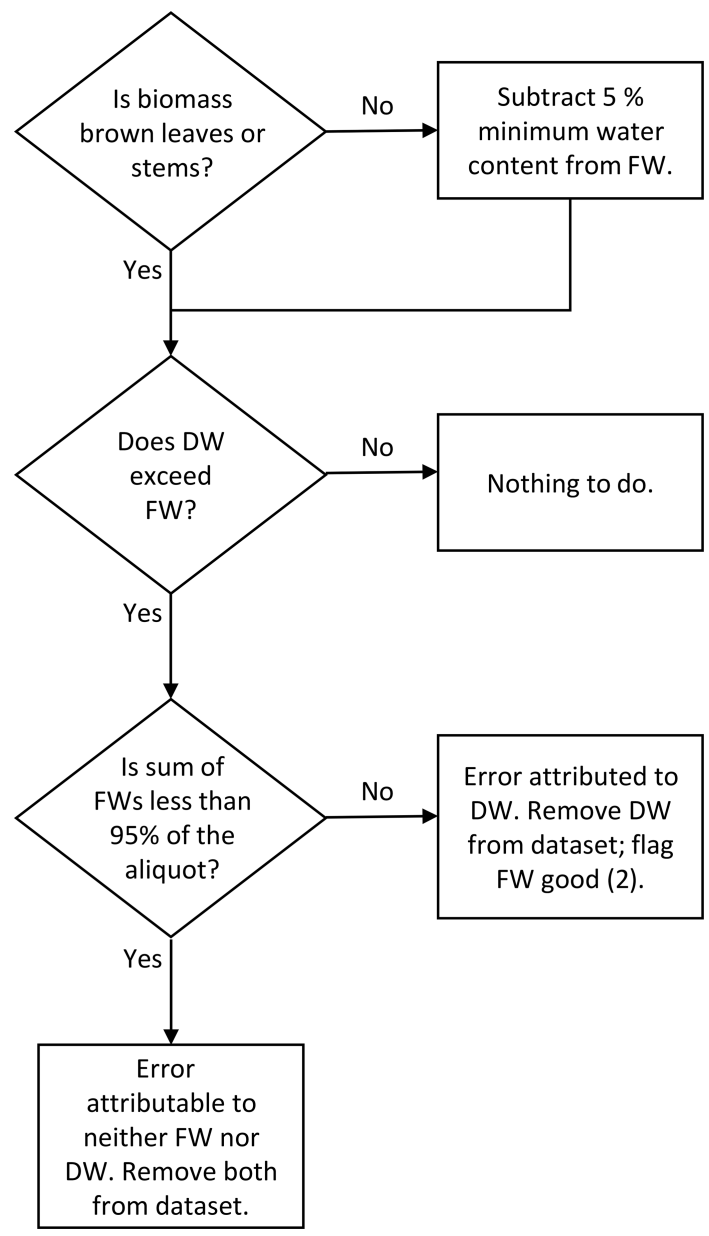

Figure 4. Flow chart of the decision process of quality assurance when fresh weight (FW) was found to be larger than dry weight (DW).

\subsubsection{Reconstruction of missing values}

If an aliquot was available but the FW of one of its components was missing, this FW was recalculated from the difference of the aliquot and the sum of the available FWs. Due to the missing value, the loss of material during sample partitioning cannot be determined. Instead, it is contained in the recalculated value, which is therefore flagged as suspicious (4). In this case, the test against the aliquot is not applicable. Thus, the other FWs were flagged as good quality (2).

\subsubsection{Comparison of fresh and dry weight}

The comparison of FW and DW can reveal errors in the biomass data. In the first step, it was tested whether DW exceeds FW (Fig. 4). For brown leaves and stems, FW and DW were compared directly, while for the other biomass categories, the $\mathrm{FW}$ was reduced by $5 \%$ for this test assuming that percentage of minimal water content. If DW exceeded the resulting $\mathrm{FW}$, it was checked whether the sum of fresh 
Table 4. Quality flags set if the sum of their components differed from the biomass aliquot.

\begin{tabular}{lllll}
\hline & $<5 \%$ & $5 \%-10 \%$ & $10 \%-15 \%$ & $>15 \%$ \\
\hline Sum $<$ aliquot & High quality (1) & Good quality (2) & Suspicious (4) & Low quality (5) \\
Sum $>$ aliquot & High quality (1) & Suspicious (4) & Suspicious (4) & Low quality (5) \\
\hline
\end{tabular}

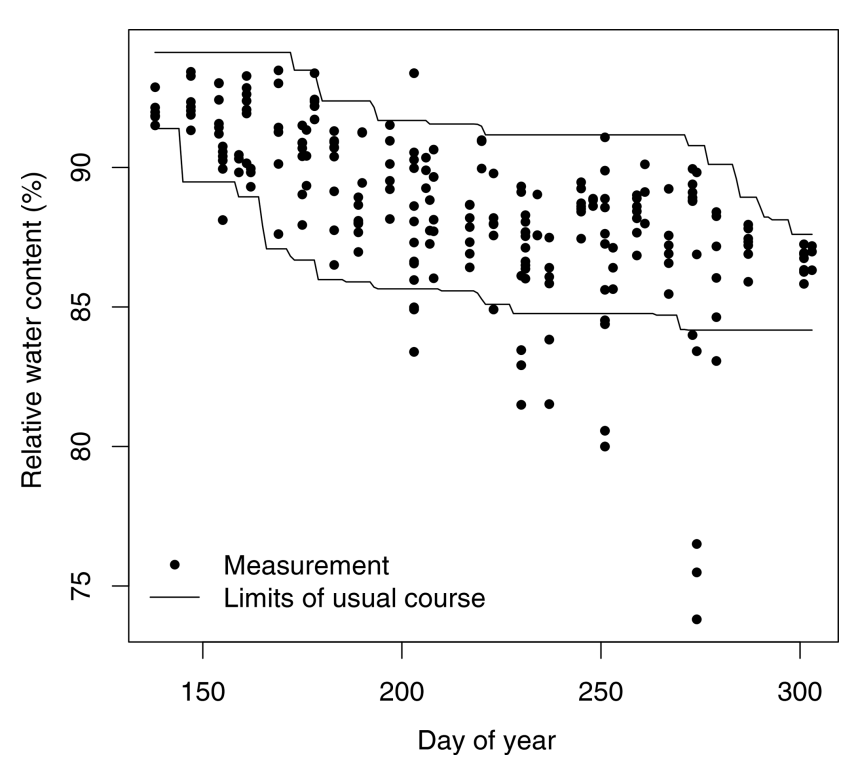

Figure 5. Temporal course of sugar beet leaves' relative water content (percentage of fresh weight, all available data). Black lines show the upper and lower limit of the "usual course" (definition in the text). Circles outside the limits of the usual course are assigned the unusual water content flag (3). These data may still be valid because of heterogeneous conditions in a field (e.g., because of earlier drying).

weights was less than $95 \%$ of the aliquot, which hints at a possible error in the FWs (see above). In that case, the error can be attributed to neither FW nor DW, and both were removed from the dataset. If the sum of fresh weights was more than $95 \%$ of the aliquot, the error was attributed to the DW, which consequently was removed from the dataset, and the corresponding FW was flagged as good quality (2).

In the second step it was checked whether the relative water content (FW - DW) / FW of green stems, green leaves, and fruit are within the range of usual values. This can hint at problems with the DW and FW, which were not identified based on either of the weight values alone. At first, it was assumed that living plant tissue has at least a water content of $50 \%$, and DW and FW of green stems or leaves were flagged as suspicious (3) if the relative water content was below $50 \%$. In addition, a "usual course" of the relative water content (Fig. 5) was defined for fruit, green leaves, and green stems for winter wheat, winter barley, rapeseed, maize, and sugar beet, respectively. In order to define a lower and up- per boundary of the usual water content, the following steps were executed:

1. Use all water content data for a respective crop and organ.

2. Exclude outliers by removing all values outside of the $10 \%$ and $90 \%$ percentiles in a running $21 \mathrm{~d}$ window.

3. In each time window, determine the corridor of 2 standard deviations above and below the mean.

Owing to the low number of data for some crops and organs and to their scattering, the upper and lower boundaries of the corridor show a lot of scatter. Since there is tendency towards lower water content with progressing phenological development, the limits of the usual course were defined as follows (Fig. 5).

4. Lower limit: for each day in the direction of time, only include the lower boundary of the corridor if it is lower than the value on the previous day. Otherwise, keep the value of the previous day as the lower limit of the usual course.

5. Upper limit: for each day in reverse direction of time, only include the upper boundary of the corridor if it is higher than the value on the following day. Otherwise, keep the value of the following day as the upper limit of the usual course.

For water content outside of the upper or lower limits, FWs and DWs were assigned the "unusual water content" flag (3). However, these data might also result from particularly dry or wet conditions at a point in a field in a certain year.

\subsubsection{Reported issues}

All issues observed in the field or in the lab which may have had an influence on the results were translated into flags. For samples reported as dirty, FW and DW were flagged as suspicious (4). For humid or wet samples, samples which might not have been completely dried, and samples which were not analyzed on the same day, only the FW was flagged as suspicious (4) since DW is not affected. If the number of plants per meter was required for upscaling (MA, SB, RA) but missing, this value was derived from other points or dates in the same management period and field. Since this propagates linearly to LAI and to all biomasses per square meter and since the germination rate is variable in space, all FWs and LAI were flagged as suspicious (4). 


\subsubsection{Propagation of quality flags}

FW and DW are connected by the upscaling process from the aliquot to the sample (see Sect. 4.1) because the upscaling factor derived from FW is also applied to DW. Therefore, flags were propagated from FW to DW and in the event of leaves also to LAI.

\subsubsection{Coordinates}

To ensure the validity of the location coordinates it was ensured that reported coordinates of a given measurement are within the given field and that no duplicate coordinates are assigned to different measurements on the same date. If it was not possible to correct implausible coordinates, they were removed. In 2008, measurement locations within each field were predefined and marked with flags. Consequentially, coordinates were not recorded explicitly. Since destructive sampling employed in this study prevents repetitive sampling of the exact same location, the prescribed coordinates represent the sampling location less accurately than those recorded directly at the sampling points. Thus, coordinates for 2008 were flagged as good quality (2) instead of high quality (1).

\subsection{Uncertainty}

Uncertainty of biomass data is difficult to estimate. Sources of error exist in all steps of sampling and analysis, including harvest of the samples in the field (incomplete harvest), loss of material and water during handling of the sample, and the unsystematic error of the scales. The error of incomplete harvest cannot be quantified based on the existing data. However, the relative error can be assumed to be rather small for high biomass. The error of handling the sample in the lab (separation of the sample) can be assessed by comparing the weight of the aliquot that was separated by organ with the sum of the organ weights. Of 1176 organ-specific records in the dataset, 229 have a valid aliquot. The other records either show missing values, only have a single organ, or were weighed in total without taking an aliquot. A total of 164 records show a loss of material during separation, while 20 show an increase. The mean loss is $2.6 \%$ of the aliquot ( $\max$ $15 \%)$. The mean increase is $2.9 \%(\max 17 \%)$. The average error for the (un-)packing steps associated with transport and drying cannot be quantified based on the available data. However, since activities are similar, it can be assumed to be of a similar relative magnitude. The maximum error of the scales used in the lab was $0.1 \mathrm{~g}$. Since leaf area can be measured quite precisely, the relative uncertainty of LAI depends primarily on the accuracy of the leaf weight used for upscaling. Since these are connected linearly in the upscaling process, it equals the relative uncertainty of biomass. A further source of error is the upscaling from the sample taken in the field to a square meter. For row crops (see Sect. 4.1), the error of the measured row spacing or plant density within the rows propagates linearly into the upscaled result. In order to reduce this error, the median of all row distances measured on a field in a management period was used for upscaling. As the sowing machine settings do not change within a field, the resulting error is considered small. In the field, plant height was measured with a folding rule. The reading accuracy is assumed to be $1 \mathrm{~cm}$, which is less than the natural variability of plant height.

The uncertainty of carbon and nitrogen content of the plant tissues was determined by analyzing differences of $1034 \mathrm{du}-$ plicate measurements (two aliquots of the same sample). For carbon content, the mean difference of the samples was $0.6 \%$. For nitrogen content, the mean difference was $1.1 \%$. The largest differences occurred for root tissues.

Concerning the uncertainty of phenological states in the $\mathrm{BBCH}$ system, principal growth stages (first digit) can be assumed to be correct, while secondary growth stages (second digit) may have an error. Since this depends on the observer, it cannot be generally quantified.

\subsection{Data format}

Vegetation data are supplied per site in a UTF-8-coded CSV file named "vegetation_" followed by the two-letter site abbreviation (Table 2). The column separator is the semicolon (;). A description of columns and units is presented in Table A1. The no-data symbol is NA. The files have two header lines, of which the first contains the variable names, while the second contains the units.

Phenological development ("bbch" column) may be given as a single number or as a range if the development state could not be exactly identified in the field. Before sowing and after harvest, the land use is set to harvest residues (HR) independent of the presence of residues on the surface of the field.

\section{Fluxes of carbon, water, and energy}

\subsection{Data source and methods}

The dataset contains 15 time series of flux measurements (Table 5). Net fluxes of carbon (net ecosystem exchange, NEE), water (latent energy, LE), and energy (sensible heat flux, H) at the surface were measured at the sites Selhausen, Merzenhausen, and Merken using state-of-the-art eddy covariance systems. There were no flux measurements in Hürtgenwald. Wind components and sonic temperature were measured with a three-dimensional sonic anemometer (CSAT3, Campbell Scientific, Inc., Logan, UT, USA). Measurements of water vapor $\left(\mathrm{H}_{2} \mathrm{O}\right)$ and carbon dioxide $\left(\mathrm{CO}_{2}\right)$ density were carried out using an open-path infrared gas analyzer (IRGA; model LI7500, LI-COR Inc., Lincoln, NE, USA). The previously unavailable data from Merken contain data for three fields where the EC towers were equipped with two sets of 
Table 5. Locations, processing software, instrument heights, and temporal extent of eddy covariance measurements. Coordinates are UTM zone 32N (WGS 1984). For information on quality indicators see Sect. 5.2.

\begin{tabular}{|c|c|c|c|c|c|c|c|c|c|c|c|}
\hline Site & Field & Year & Identifier & UTM N & UTM E & $\begin{array}{r}\text { Elevation } \\
\text { (ma.s.1.) }\end{array}$ & $\begin{array}{l}\text { Processing } \\
\text { software }\end{array}$ & $\begin{array}{l}\text { Quality } \\
\text { indicator }\end{array}$ & $\begin{array}{r}\text { Height }^{\mathrm{a}} \\
(\mathrm{cm})\end{array}$ & $\begin{array}{r}\text { Start }^{b} \\
(\text { yyyy-mm-dd) }\end{array}$ & $\begin{array}{r}\text { End }^{\mathrm{b}} \\
\text { (yyyy-mm-dd) }\end{array}$ \\
\hline SE & F08 & 2007 & SEF08_SE_EC000_fluxes_2007 & 5638560 & 320543 & 103 & TK2 & Flags & 245 & $2007-05-25$ & $2007-12-25$ \\
\hline SE & F08 & 2008 & SEF08_SE_EC000_fluxes_2008 & 5638560 & 320543 & 103 & TK2 & Flags & 245 & 2008-01-08 & $2008-12-31$ \\
\hline SE & F08 & 2009 & SEF08_SE_EC000_fluxes_2009 & 5638560 & 320543 & 103 & TK2 & Flags & 245 & 2009-01-01 & $2009-12-31$ \\
\hline SE & F08 & 2010 & SEF08_SE_EC000_fluxes_2010 & 5638560 & 320543 & 103 & TK2 & Flags & 245 & 2010-01-01 & $2010-10-14$ \\
\hline SE & F01 & 2015 & SEF01_SE_EC001_fluxes_2015 & 5638010 & 320380 & 103 & TK3.1 & Flags & 245 & 2015-01-01 & $2015-12-31$ \\
\hline SE & F01 & 2016 & SEF01_SE_EC001_fluxes_2016 & 5638010 & 320380 & 103 & TK3.1 & Flags & 245 & 2016-01-01 & $2016-12-31$ \\
\hline ME & F01 & 2011 & MEF01_ME_EC001_fluxes_2011 & 5645497 & 310059 & 93 & TK3.1 & Flags & 198 & 2011-05-10 & 2011-12-31 \\
\hline ME & F01 & 2012 & MEF01_ME_EC001_fluxes_2012 & 5645497 & 310059 & 93 & TK3.1 & Flags & 198 & 2012-01-01 & $2012-12-31$ \\
\hline ME & F01 & 2017 & MEF01_ME_EC001_fluxes_2017 & 5645497 & 310059 & 93 & TK3.1 & Flags & 198 & 2017-01-01 & $2017-12-31$ \\
\hline MK & F02 & 2009 & MKF02_MK_ECJ11_fluxes_2009 & 5635998 & 316798 & 116 & ECpack 2.5.20 & Tolerances & 240 & 2009-04-14 & $2009-08-27$ \\
\hline MK & F02 & 2009 & MKF02_MK_ECJ1u_fluxes_2009 & 5635998 & 316798 & 116 & ECpack 2.5.20 & Tolerances & 590 & 2009-04-07 & $2009-08-27$ \\
\hline MK & F03 & 2009 & MKF03_MK_ECS41_fluxes_2009 & 5636165 & 317010 & 114 & ECpack 2.5.20 & Tolerances & 260 & 2009-04-07 & 2009-09-03 \\
\hline MK & F03 & 2009 & MKF03_MK_ECS4u_fluxes_2009 & 5636165 & 317010 & 114 & ECpack 2.5.20 & Tolerances & 596 & 2009-04-21 & 2009-09-07 \\
\hline MK & F04 & 2009 & MKF04_MK_ECS31_fluxes_2009 & 5635956 & 317204 & 115 & ECpack 2.5.20 & Tolerances & 248 & 2009-04-09 & 2009-09-29 \\
\hline MK & F04 & 2009 & MKF04_MK_ECS3u_fluxes_2009 & 5635956 & 317204 & 115 & ECpack 2.5.20 & Tolerances & 604 & $2009-04-23$ & 2009-09-15 \\
\hline
\end{tabular}

${ }^{\mathrm{a}}$ Height: instrument height of anemometer and infrared gas analyzer (above ground). ${ }^{\mathrm{b}}$ First and last day with valid data: $\mathrm{y}-$ year; $\mathrm{m}-$ month; $\mathrm{d}-$ day.

sensors at different heights. The lower measurement height is usually more representative of the respective land use type. However, the upper level has provided an even better energy balance closure than the already good one of the lower level.

Measurements were taken with a sampling rate of $20 \mathrm{~Hz}$ and were aggregated to intervals of $30 \mathrm{~min}$. Processing of raw measurements was accomplished as shown in Fig. 1 of Mauder et al. (2013) using the processing software shown in Table 5. The number of decimal places in the data files was kept as they were in the output of the processing software. No gap filling was applied to the data.

Examples of the application of the flux data can be found in Ahrends et al. (2014), Eder et al. (2015), Klosterhalfen et al. (2017), Ney and Graf (2018), Schmidt et al. (2012), and Wienecke et al. (2018).

\subsection{Quality assurance}

Quality control was accomplished according to the "TERENO" scheme for quality and uncertainty assessment presented by Mauder et al. (2013). Deviating from this description, before 2011 the software TK2 (Mauder and Foken, 2011) was applied following the process described in Sect. 2.3 of Schmidt et al. (2012). The software ECpack 2.5.20 (Van Dijk et al., 2004) was applied for the data from Merken (Table 5). The software TK uses flagging to indicate the quality of data. Flag values and their meanings are shown in Table 6.

Since flux data from Merken 2009 (MK09) was processed with the ECpack software, the concept of quality assurance differs from the other sites. ECpack provides tolerance values which can be used to rate the quality of data (Table 7). Values outside the lower and upper boundaries given in Table 7 are considered invalid. In addition, data can be filtered using the tolerance values. A tolerance is assigned to the lower and upper boundary of each variable, respectively. To evaluate the quality of the data in the valid ranges, tolerances have to be linearly interpolated between the boundaries. The most obvious tolerance violations have already been eliminated by a postprocessing scheme. Tolerance limits were set sufficiently wide to retain most of the values which still might be useful in the dataset. For some variables, considering a value to be invalid causes the whole record to be invalid. These variables are assigned to group A in Table 7. If any value of group B is considered invalid, only the values of group B are invalid.

\subsection{Uncertainty}

Uncertainty information for fluxes per data point is available for sensible heat flux, latent heat flux, NEE, and friction velocity. The kind of uncertainty information differs between the different software tools used for data processing (Table 5). For TK3, relative random errors and relative noise errors for friction velocity, sensible and latent heat flux, and net ecosystem exchange are given in the respective columns (see Table A3) in the data files. For datasets processed with TK2 this information is not available. A rough estimate of the general uncertainty for these measurements may be obtained from statistics of the errors included given in the TK3processed data. For other variables included in the TK output, the uncertainty is quantified from the instrument errors given by the respective manufacturers (Table 11). The uncertainties of $\mathrm{CO}_{2}$ and water content of the air (variables $\mathrm{CO} 2$ and a; see Table A3) strongly depend on calibration. Detailed information can be obtained from the manual of the infrared gas analyzer (LiCOR LI7500, LI-COR Inc., Lincoln, NE, USA). However, the accuracy of the absolute measurements is of minor importance for the eddy covariance method since it depends on relative changes. The other software tool, ECpack, calculates $95 \%$ confidence intervals per data point for fluxes and several other variables. These so-called tolerances are given in the respective columns (see Table A2) in the data files. Additional information on uncertainties of eddy covariance measurements is presented by Mauder et al. (2013). 
Table 6. Flag values set by the TK software and their meanings.

\begin{tabular}{ll}
\hline Flag & Meaning \\
\hline 0 & High-quality data, use in fundamental research possible \\
1 & Moderate-quality data, no restrictions for use in long-term observation programs \\
2 & Low data quality, gap filling necessary \\
\hline
\end{tabular}

Table 7. Acceptable value ranges of ECpack results and tolerance values at the lower and upper boundary. For the meaning of the "Group" column refer to the text.

\begin{tabular}{lrrrrr}
\hline Variable & $\begin{array}{r}\text { Lower } \\
\text { boundary }\end{array}$ & $\begin{array}{r}\text { Tolerance at } \\
\text { lower boundary }\end{array}$ & $\begin{array}{r}\text { Upper } \\
\text { boundary }\end{array}$ & $\begin{array}{r}\text { Tolerance at } \\
\text { upper boundary }\end{array}$ & Group \\
\hline Mean(u) & 0 & 0.2 & 200 & 1 & $\mathrm{~A}$ \\
Mean(w) & 0 & 0.05 & 20 & 0.1 & $\mathrm{~A}$ \\
Mean(TSon) & 273.15 & 0.1 & 350 & 0.1 & $\mathrm{~A}$ \\
Mean(rhoV) & 0 & $2 \times 10^{-4}$ & 0.2 & $2 \times 10^{-4}$ & $\mathrm{~B}$ \\
Mean(qCO2) & $4 \times 10^{-4}$ & $1 \times 10^{-5}$ & $1 \times 10^{-3}$ & $1 \times 10^{-5}$ & $\mathrm{~B}$ \\
U_dir & 0 & 180 & 360 & 180 & $\mathrm{~A}$ \\
Hsonic & 0 & 25 & 1000 & 100 & $\mathrm{~A}$ \\
SumLvE & 0 & 50 & 1000 & 200 & $\mathrm{~B}$ \\
Ustar & 0 & 0.2 & 1.0 & 0.3 & $\mathrm{~A}$ \\
SumFCO2 & 0 & $5 \times 10^{-7}$ & $5 \times 10^{-6}$ & $1 \times 10^{-6}$ & $\mathrm{~B}$ \\
\hline
\end{tabular}

\subsection{Data format}

Flux data are provided in a UTF-8-coded CSV file per field and year. The file name consists of "fluxes_" followed by the two-letter site abbreviation (Table 2), the field ID (Fig. 1), "EC", a station identifier, and the year. The elements of the file name are separated by underscores (e.g., fluxes_SEF01_EC_001_2016.csv). The column separator is the semicolon (;). A description of columns and units is presented in Tables A2 and A3 for the TK and ECpack software, respectively. The no-data symbol is NA. The files have two header lines, of which the first contains the variable names, while the second contains the units.

\section{Soil properties}

\subsection{Data source and methods}

Soil property data include particle size distribution of the fine soil $(<2 \mathrm{~mm})$, proportion of coarse material (gravel, $>2 \mathrm{~mm}$ ), bulk density, and soil carbon and nitrogen content. The availability of data differs from site to site (Table 8).

All particle sizes were analyzed following DIN ISO 11277. Therefore, they follow the definition of particle size classes of DIN 14688. Particles larger than $2 \mathrm{~mm}$ are considered gravel. To recalculate particle sizes to the USDA system, which is assumed for many pedotransfer functions, refer to, e.g., Nemes et al. (1999). All data on particle sizes and soil carbon or nitrogen content refer to fine soil after the removal of gravel. Therefore, percentages of sand, silt, and clay refer to fine soil, while the percentage of gravel refers to total soil mass. Bulk density was determined gravimetrically. Total $\mathrm{C}$ concentrations in soil samples were determined by elemental analysis. Based on previous analyses it can be assumed that all samples were free of carbonates. Hence, total $\mathrm{C}$ concentrations are in accordance with those of soil organic carbon (SOC).

Applications of the soil data can be found in Bornemann et al. (2011), Brogi et al. (2019, 2020), Jakobi et al. (2020), Korres et al. (2013), and Meyer et al (2017).

\subsubsection{Selhausen}

Soil data for Selhausen originate from different sources. Particle sizes for three depths in field SE F08 were analyzed at the Laboratory for Physical Geography, University of Cologne. For the plowing horizon of field SE F00, particle sizes were analyzed at the Institute of Crop Science and Resource Conservation, University of Bonn (Bornemann et al., 2011). These data have a high spatial resolution that enables analysis of small-scale heterogeneity. A third dataset consists of horizon-specific particle size data from 100 randomly chosen points from a $1 \mathrm{~km}^{2}$ area that includes most fields with vegetation data. The samples were analyzed at the Soil Physical Laboratory of IBG-3, Jülich Research Centre, using a Sedimat 4-12 apparatus (UGT, Umwelt Geräte Technik GmbH, Münchenberg, Germany). From these data and extensive electromagnetic induction (EMI) measurements, Brogi et al. (2019) generated a map of soil units, which groups the abovementioned 100 sampling locations into 18 geophysics-based soil units composed of 2 to 12 sampling 
Table 8. Availability of soil information per site. $\mathrm{C}$ and/or N: both carbon and nitrogen content is not always available. Due to the absence of carbonates, $\mathrm{C}$ content is expected to equal soil organic carbon (SOC).

\begin{tabular}{lccccc}
\hline Site & Particle sizes of fine soil & Gravel & Bulk density & SOC & C and/or N \\
\hline HW & X & X & X & - & - \\
MK & $X$ & - & - & - & X \\
ME & $X$ & $X$ & $X$ & $X$ & X \\
SE & $X$ & $X$ & $X$ & - & X \\
\hline
\end{tabular}

locations. These soil units are also provided with a quantitative description (layering, texture, total carbon and nitrogen content) of the soil profile. In the files containing information on the soil and vegetation samples, a column (soil_unit) establishes the link to the respective soil unit. For several fields, total carbon and nitrogen content for three depths was determined from composite samples at the Laboratory for Physical Geography, University of Cologne, using a CNS elemental analyzer (Vario EL, Elementar Analysensysteme GmbH, Hanau, Germany). If data were available for several dates, a date after harvest but before the next fertilizer application was preferred if possible. This is noted in the comments column of the data table. Soil carbon and nitrogen data are assigned to a field instead of a specific location because a composite sample containing equal fractions of material from several points was analyzed.

From the 100 sampling points of the $1 \mathrm{~km}^{2}$ area, carbon and nitrogen content for two horizons (Ap and Bw) was determined for composite samples from all sampling points within a soil unit, respectively. Therefore, these data are given per soil unit. To determine nitrogen and carbon content, a standard combustion method was used at the Geography Institute of the Ruhr University Bochum using a CNS elemental analyzer (Vario Max, Elementar Analysensysteme $\mathrm{GmbH}$, Hanau, Germany). All samples were collected between 6 and 15 February 2017. It has to be noted that samples were collected regardless of the agricultural management.

Due to temporal and spatial variability, these data have to be understood as snapshots and cannot be transferred to other points in space or time.

\subsubsection{Merken}

Particle size data for the Merken site are only available from a composite sample based on samples from all fields. These data are assumed to be valid for all fields due to small spatial heterogeneity of the soil at the site. The analysis was carried out at the Soil Physical Laboratory of IBG-3, Jülich Research Centre. Field-specific carbon and nitrogen content for three soil depths was measured from composite samples as described for Selhausen.

\subsubsection{Merzenhausen}

For the field in Merzenhausen, soil texture, bulk density, and content of carbon and nitrogen were determined for the Ap horizon at a single point in the field following the methodology described by Bornemann et al. (2011). Bulk density was quantified from three independent $100 \mathrm{~cm}^{3}$ samples. Since no data were collected for other soil horizons in the framework of the TR32 project, we include data published by Pütz (1993) for the sake of completeness.

\subsubsection{Hürtgenwald}

For Hürtgenwald, particle sizes were analyzed at the Institute of Crop Science and Resource Conservation, University of Bonn, while bulk densities were determined at the Laboratory for Physical Geography, University of Cologne.

\subsection{Quality assurance}

For the determination of particle sizes, bulk density, and carbon and nitrogen content, at least two samples from each point were analyzed in parallel. This was not the case for the $1 \mathrm{~km}^{2}$ data from Selhausen, where single analyses were carried out. In this case, the weight of the sample was taken before and after the texture analysis. The analysis was repeated if the final weight was lower than $95 \%$ of the initial weight. If at the second iteration the value was again lower than $95 \%$, the analysis was repeated for a third time.

\subsection{Uncertainty}

To quantify the uncertainty of particle size fractions, data of a repeatedly analyzed sample were evaluated at the University of Bonn. The results show coefficients of variation (CVs) of $2.0 \%$ for sand, $2.4 \%$ for silt, $2.5 \%$ for clay, and $3.5 \%$ for gravel. Since such repeated estimates were not performed at the University of Cologne, it is assumed that the uncertainty of their measurements is of the same magnitude. At Jülich Research Centre, particle sizes were automatically analyzed with a Sedimat (see above), which has uncertainties in the calculation of the particle size fractions that are comparable to those obtained in the abovementioned analysis performed in Bonn. For bulk density, a CV of $10 \%$ was determined from the analysis of multiple adjacent samples from 
the same horizon (University of Bonn). For the soil unit data from Selhausen, uncertainties for particle size fractions and layer depth are given in the respective columns (Table A6) in the data files. The CNS elemental analyzers used to determine soil carbon and nitrogen content show uncertainties of $\pm 0.01 \%$ for carbon and $\pm 0.002 \%$ for nitrogen.

\subsection{Data format}

Soil data are provided in a UTF-8-coded CSV file per site named "soil_" followed by the two-letter site abbreviation (Table 2). The column separator is the semicolon (;). A description of columns and units is presented in Table A5. The no-data symbol is NA. Soil unit data for Selhausen are provided in a UTF-8-coded CSV file named "soil_units_SE.csv". The column separator is the semicolon (;). A description of columns and units is presented in Table A6. The files have two header lines, of which the first contains the variable names, while the second contains the units.

\section{Meteorological data}

\subsection{Data source and methods}

The dataset was assembled with the aim of providing the data usually required to run a hydroecological crop growth model. Therefore, the dataset includes gap-filled hourly meteorological data of air pressure (AirPres; Pa), global radiation (Globrad; $\mathrm{W} \mathrm{m}^{-2}$ ), air temperature (AirTemp; K), relative air humidity (AirHum; \%), wind speed (Wind; $\mathrm{m} \mathrm{s}^{-1}$ ), precipitation (Precip; $\mathrm{mm} \mathrm{h}^{-1}$ ), incoming longwave radiation (InLW; $\mathrm{W} \mathrm{m}^{-2}$ ), and cloudiness (Cloudiness; $1 / 8$ ). The meteorological data starts about 1 year earlier than the vegetation data to provide data for model spin-up concerning water pools in the vadose zone.

The availability of meteorological field data varies between the sites as well as in time. The temporal availability of data increased significantly with time due to the setup of the meteorological stations of the TERENO Eifel/Lower Rhine Valley observatory in 2011. In the earlier years, only a few meteorological stations were run near the sites. Table 9 shows a list of all meteorological stations used in this study. Methods to fill gaps in the time series vary between years and stations. The gap-filling methods are explained in the following sections. The data sources for each year and site are presented in Table 10. In most cases, information on the measurement devices and raw data with gaps can be obtained from the data sources shown in the table.

Meteorological data for the site Hürtgenwald are provided for the years 2014 through 2016. Meteorological measurements started on 21 April 2015 (station 20 in Table 9). In 2016, additional stations were set up nearby (station 21 in Table 9). Data for earlier dates were generated using the regression gap-filling method (see Sect. 7.1.1) for all variables but AirPres, where gaps were filled using the barometric formula (Eq. 1). The first year for HW consists of reconstructed data only.

Data for the site Merzenhausen are provided for the years 2009 through 2017. Local measurements are available for the whole period (stations 1 and 15 in Table 9). For the years 2009 and 2010, gaps were filled using the regression method. From 2011 on, the EOF (empirical orthogonal function) method was used (see Sect. 7.1.1).

Data for Selhausen are provided for the years 2007 through 2017. Local measurements are available for the whole period, starting on 27 May 2007 (stations 10, 11, and 19 in Table 9). For the years 2007 until 2010, the regression method was used to fill gaps. From 2011 on, the EOF method was applied.

For the site Merken, no meteorological data are available. Since the distance to Selhausen is only about $4 \mathrm{~km}$, and the difference in elevation is about $10 \mathrm{~m}$, it can be assumed that the weather was very similar to that in Selhausen. Therefore, the use of Selhausen meteorological data when working with Merken vegetation or flux data is suggested.

Since cloudiness is not available for any of the sites but required in some ecohydrological models (e.g., the DANUBIA simulation system; for an application see, e.g., Korres et al., 2013), data on cloudiness from the Aachen station of the German Meteorological Service (distances to HW, ME, and $\mathrm{SE}$ are 37, 37, and $42 \mathrm{~km}$, respectively) were used. Since there is no reliable method to adjust cloudiness data to remote stations, the data were used without modifications.

Information on the conditions at the locations of the meteorological stations, especially in the past, are not fully available. Therefore, precipitation data are given as measured at the stations. Since the data were not corrected for shielding effects, precipitation can be assumed to be slightly underestimated.

Figure 6 shows an excerpt of the meteorological data for the Selhausen site for the period May to July 2011. The graphs show a period where there are no breaks or shifts in the continuous curves, which is the usual case in the weather time series (for a discussion of inhomogeneities, see Sect. 7.1.3). In the middle of June, the example data show a noticeable period of $2 \mathrm{~d}$ with low radiation and temperatures together with rather high wind speed and high cloud cover. All variables show a reduced diurnal cycle, which confirms the consistency of the time series of the separate variables and is an important prerequisite for a good reproduction of real processes in a simulation.

Applications of the meteorological data can be found in Korres et al. (2013), Ney and Graf (2018), Sakai et al. (2016), and Schmidt et al. (2012).

\subsubsection{Gap filling}

In the course of the TR32 project, an increasing number of meteorological stations were set up in the Rur catchment. 
Table 9. Meteorological stations, their positions, available data, and data source.

\begin{tabular}{|c|c|c|c|c|c|c|c|c|c|c|c|c|}
\hline ID & Station & UTM northing & UTM easting & Period used & $\underset{\Xi}{\Xi}$ & $\stackrel{\mathscr{d}}{\stackrel{0}{\sharp}}$ & 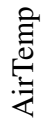 & $\begin{array}{l}\text { ने } \\
0 \\
0\end{array}$ & $\begin{array}{l}\vec{\pi} \\
\frac{\pi}{0} \\
\frac{0}{0}\end{array}$ & $\vec{B}$ & $\frac{\overrightarrow{0}}{\bar{U}}$ & Data source \\
\hline 1 & ME_BCK_001 & 5645555 & 310095 & 2011-2016 & $X$ & $X$ & & $X$ & $X$ & $X$ & & TEODOOR $^{1}$ \\
\hline 2 & RO_AKRW_003 & 5611891 & 309102 & 2011-2016 & $X$ & $X$ & $X$ & $X$ & & $X$ & & TEODOOR $^{1}$ \\
\hline 3 & RO_BKY_010 & 5611219 & 309322 & 2012-2016 & $\mathrm{X}$ & $\mathrm{X}$ & $\mathrm{X}$ & $\mathrm{X}$ & $\mathrm{X}$ & $\mathrm{X}$ & & TEODOOR $^{1}$ \\
\hline 4 & RO_EC_001 & 5611250 & 309312 & 2011-2016 & $X$ & $X$ & $X$ & $\mathrm{X}$ & $X$ & $X$ & & TEODOOR $^{1}$ \\
\hline 5 & RU_BCK_002 & 5652036 & 312165 & 2011-2016 & $\mathrm{X}$ & $\mathrm{X}$ & $\mathrm{X}$ & $\mathrm{X}$ & $X$ & $X$ & & TEODOOR $^{1}$ \\
\hline 6 & RU_BCK_003 & 5637669 & 318956 & 2011-2016 & $X$ & $X$ & $\mathrm{X}$ & $\mathrm{X}$ & & $\mathrm{X}$ & & TEODOOR $^{1}$ \\
\hline 7 & RU_BCK_004 & 5668397 & 301947 & 2012-2016 & $X$ & $X$ & $X$ & $\mathrm{X}$ & & $X$ & & TEODOOR $^{1}$ \\
\hline 8 & RU_BCDKR_001 & 5599172 & 313945 & 2011-2016 & $\mathrm{X}$ & $X$ & $X$ & $X$ & $\mathrm{X}$ & $X$ & & TEODOOR $^{1}$ \\
\hline 9 & RU_K_002 & 5642873 & 317452 & 2013-2016 & $X$ & $\mathrm{X}$ & $\mathrm{X}$ & $X$ & $X$ & $X$ & & TEODOOR $^{1}$ \\
\hline 10 & SE_BDK_999 & 5638335 & 320536 & 2009-2016 & $X$ & $X$ & $\mathrm{X}$ & $\mathrm{X}$ & $\mathrm{X}$ & $\mathrm{X}$ & & TEODOOR $^{1,3}$ \\
\hline 11 & SE_EC_001 & 5638012 & 320375 & 2011-2016 & $\mathrm{X}$ & $X$ & $\mathrm{X}$ & $\mathrm{X}$ & $\mathrm{X}$ & $\mathrm{X}$ & & TEODOOR $^{1}$ \\
\hline 12 & WU_BKY_010 & 5597950 & 310540 & 2012-2016 & $X$ & $X$ & $\mathrm{X}$ & $X$ & $X$ & $X$ & & TEODOOR $^{1}$ \\
\hline 13 & WU_EC_002 & 5597955 & 311089 & 2013-2016 & $X$ & $X$ & $X$ & & $X$ & $\mathrm{X}$ & & TEODOOR $^{1}$ \\
\hline 14 & WU_K_002 & 5597960 & 311091 & 2014-2016 & $X$ & $X$ & $X$ & $X$ & & $\mathrm{X}$ & & TEODOOR $^{1}$ \\
\hline 15 & ME_EC_001 & 5645497 & 310059 & 2011-2016 & $X$ & $X$ & $\mathrm{X}$ & $\mathrm{X}$ & $X$ & $X$ & & TEODOOR $^{1}$ \\
\hline 16 & RU_K_001 & 5643013 & 317883 & 2007-2016 & $X$ & $X$ & & $X$ & $X$ & $X$ & & TEODOOR $^{1}$ \\
\hline 17 & RU_EC_001 & 5637813 & 318969 & 2011-2016 & $X$ & $X$ & $X$ & & $X$ & $X$ & & TEODOOR $^{1}$ \\
\hline 18 & WU_EC_001 & 5598173 & 310739 & 2011-2014 & $X$ & $X$ & $\mathrm{X}$ & & $X$ & $\mathrm{X}$ & & TEODOOR $^{1}$ \\
\hline 19 & SE_EC_002 & 5638375 & 320591 & 2010 & $X$ & $X$ & $X$ & $X$ & $X$ & $X$ & & TEODOOR $^{1}$ \\
\hline 20 & HW_BK_001 & 5622292 & 314567 & 2015-2016 & $X$ & $X$ & $X$ & $X$ & $X$ & $X$ & & GLOBE $^{4}$ \\
\hline 21 & HW_BK_002 & 5621923 & 314600 & 2016 & $X$ & $X$ & $X$ & $X$ & $X$ & $X$ & & GLOBE $^{4,5}$ \\
\hline 22 & 10501 & 5629698 & 295161 & 2007-2010 & & $X$ & & & & & $X$ & DWD $^{6,7}$ \\
\hline 23 & 10505 & 5631617 & 290318 & 2011-2016 & & & & & & & $X$ & DWD $^{6,8}$ \\
\hline 24 & H827 & 5616739 & 317991 & 2014-2015 & $X$ & & $X$ & $X$ & & $X$ & & DWD $^{6}$ \\
\hline 25 & SE_EC_000 & 5638537 & 320558 & 2007-2009 & $\mathrm{X}$ & $X$ & $X$ & $\mathrm{X}$ & $X$ & $\mathrm{X}$ & & $\mathrm{TR} 32 \mathrm{DB}^{2}$ \\
\hline
\end{tabular}

${ }^{1}$ http://teodoor.icg.kfa-juelich.de/ibg3searchportal2/ (last access: 1 October 2019), Eifel/Lower Rhine Valley Observatory.

2 http://www.tr32db.de (last access: 1 October 2019).

${ }^{3}$ Includes data from stations SE_BK_001and SE_BDK_002 from TEODOOR ${ }^{1}$.

4 https://datasearch.globe.gov/ (last access: 1 October 2019).

${ }^{5}$ Consists of three stations.

${ }^{6}$ German Meteorological Service, DWD, ftp://ftp-cdc.dwd.de/pub/CDC/observations_germany/climate/hourly/ (last access: 1 October 2019).

7 DWD station Aachen, old location.

${ }^{8}$ DWD station Aachen, new location.

Therefore, different methods were chosen for different periods to fill gaps in the meteorological data.

\section{Insertion method}

For this simple approach (method 0 in Table 10), data of a nearby station were simply inserted into gaps of the reference station's time series. This method was applied in the beginning of the project when only a few stations were set up.

\section{Regression method 1}

This method (method 1 in Table 10) was applied to fill gaps in Hürtgenwald. This method was applied because Hürtgenwald was not included in the central TR32 gap-filling efforts with the EOF method (see below) since it was not an offi- cial site of TR32 stations. A simple linear regression was set up between the available data of the station with gaps and a nearby station for each variable, respectively. The slope of the regression was then applied to the data of the nearby station to fill the gap. In the event of a data gap at the nearby station, data from a further station were used. In the seldom cases where no data were available at any station, the gap was filled based on linear interpolation. No gaps longer than $4 \mathrm{~h}$ had to be filled this way.

\section{Regression method 2}

For variant 2 of the regression method (method 2 in Table 10), which was applied for the year 2010 in Selhausen and for the years 2009 and 2010 in Merzenhausen, the data of a reference station were correlated with data of the closest remote station using a reduced major axis regression (Webster, 
Table 10. Source of meteorological data given as station IDs as defined in Table 9. Station IDs in parentheses are stations used for gap filling. The "Met" column shows the method used for gap filling as explained in the text.

\begin{tabular}{|c|c|c|c|c|c|c|c|c|}
\hline Year & AirPres & GlobRad & AirTemp & AirHum & Wind & Precip & Cloud & Met \\
\hline \multicolumn{9}{|c|}{ Hürtgenwald (HW) } \\
\hline 2014 & $4(24)$ & $4(24)$ & $4(24)$ & $4(24)$ & $4(24)$ & $4(24)$ & 23 & 1 \\
\hline 2015 & $20(4,24)$ & $20(4,24)$ & $20(4,24)$ & $20(4,24)$ & $20(4,24)$ & $20(4,24)$ & 23 & 1 \\
\hline 2016 & $20(4)$ & $20(21)$ & $20(21)$ & $20(21)$ & $20(21)$ & $20(21)$ & 23 & 1 \\
\hline \multicolumn{9}{|c|}{ Selhausen (SE) } \\
\hline 2007 & $25(22)$ & 22 & $25(16)$ & $25(16)$ & $25(16)$ & 16 & 22 & 0 \\
\hline 2008-2009 & $25(22)$ & 22 & $25(16)$ & $25(16)$ & $25(10,16)$ & 16 & 22 & 0 \\
\hline 2010 & 22 & $11(19,10,16)$ & $11(19,10,16)$ & $10(16)$ & $11(19,10,16)$ & 16 & 22 & 2 \\
\hline 2011-2017 & $10(1-18)$ & $11(1-18)$ & $10(1-18)$ & $10(1-18)$ & $11(1-18)$ & $10(1-18)$ & 23 & 3 \\
\hline \multicolumn{9}{|c|}{ Merzenhausen (ME) } \\
\hline 2009-2010 & 22 & $15(1,16)$ & $15(1,16)$ & $15(1,16)$ & $15(1,16)$ & $15(1,16)$ & 22 & 2 \\
\hline 2011-2017 & $1(2-18)$ & $15(1-18)$ & $1(2-18)$ & $1(2-18)$ & $1(2-18)$ & $1(2-18)$ & 23 & 3 \\
\hline
\end{tabular}

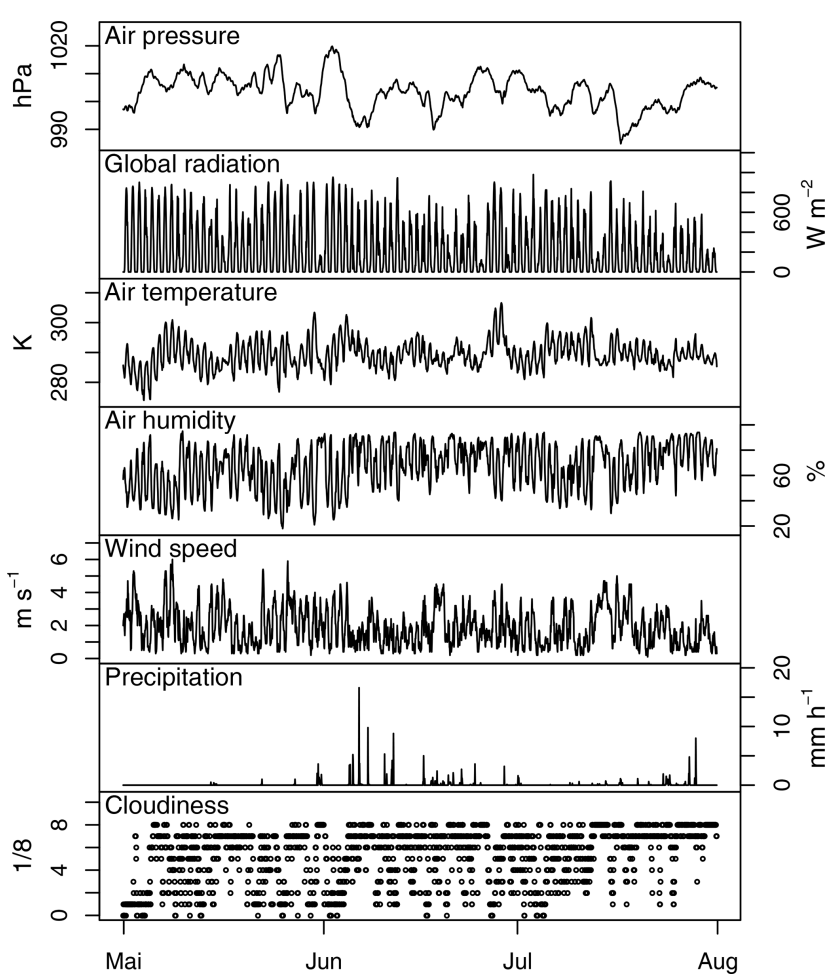

Figure 6. Excerpt of the gap-filled hourly meteorological data for the Selhausen site for the period from May until July 2011.

1997). If the coefficient of determination was higher than 0.9 , the data of the remote station were inserted into the data gap without further processing (same as insertion method). If $R^{2}$ was lower than 0.9, the slope of the regression (for AirTemp also the offset) was applied before inserting data into the data gap. For AirHum, the method was applied to dew point temperatures, which were converted back to relative humidity after gap filling. This method was the first central gap-filling effort in the project. Due to the lack of enough stations, the EOF method was not applicable in that period.

\section{EOF method}

This method (method 3 in Table 10) was applied for the sites Merzenhausen and Selhausen from 2011 on as soon as enough stations were available in the TR32 set of meteorological stations. It utilizes empirical orthogonal functions (EOFs) to describe the relation between variables at several meteorological stations. The approach was originally introduced by Beckers and Rixen (2003) and adapted for station time series by Graf (2017); further information on EOF computation on similar data can be found in Graf et al. (2012). Since the approach does not depend on the regular spatial arrangement of the pixels, it can easily be transferred to a network of stations. In contrast to the original approach, this method works on the $z$ transform of each time series (normalization by dividing the deviations from the mean by the standard deviation), which ensures that stations where the variable has a low amplitude receive the same importance as a predictor as others with a larger amplitude. The following steps were accomplished for each variable separately. Shortwave incoming (global) and photosynthetically active radiation, however, were treated jointly due to their close linear relation.

0. Prior to gap filling, remove all values rated "bad" or "suspicious".

1. Delete an additional $10 \%$ (randomly selected) of the available data per station, and set them aside for crossvalidation purposes. 
2. Perform a $z$ transform on the data for each station and variable, respectively.

3. Replace all missing values with zeroes.

4. Compute the EOFs, and reconstruct the time series of each station and variable using only the first EOF ("truncated reconstruction").

5. Fill all gaps with the reconstruction, and repeat step 4 with the filled time series. Repeat the procedure until no data point is changed from one iteration to the next by more than $1 \%$, if the change between iterations starts to increase again in at least one data point, or if a maximum of 1000 iterations is reached.

6. Use the dataset with the new preliminary fillers to initialize at step 4 again but this time using the first two EOFs. Continue as in step 5. After this has converged too, use the first 3 EOFs and so on until 10 EOFs are used.

7. Retransform results to absolute values (reverse step 2).

8. Use the cross-validation dataset set aside in step 1 to determine the number of EOFs at which the prediction is optimal (minimum RMSE between validation data and prediction). Repeat the whole procedure up to this number of EOFs starting with step 2 (i.e., without removing cross-validation data).

An advantage of this approach is that the EOF method exploits the same underlying statistics as multiple linear regression would but does not need to be re-evaluated each time a predictor variable becomes unavailable. The method was applied to $10 \mathrm{~min}$ resolution data from stations 1 to 18 (Table 9). Results were aggregated to hourly resolution.

\section{Gap filling of cloudiness data}

Gaps in cloudiness data were filled using the "na.approx" method in the R package "zoo" (Zeileis and Grothendieck, 2005).

\subsubsection{Adjustment of atmospheric pressure}

For the sites and years where the EOF method was not applied, air pressure data were transformed between stations by using the barometric formula

AirPres $=\operatorname{AirPres}_{\mathrm{r}}\left(1-\left(0.0065 \frac{\Delta h}{\text { AirTemp }}\right)\right)^{5.255}$,

where $\Delta h$ is the elevation difference between stations (m), AirTemp is the air temperature (K), and AirPress is the atmospheric pressure at the remote station $(\mathrm{hPa})$.

\subsubsection{Inhomogeneities}

A closer look at the time series of meteorological data reveals differences in general characteristics between different years. This is mainly due to different instruments or different calibration of instruments. By these means, synthetic breaks in the time series are generated that can disturb the analysis of real phenomena. This is particularly a problem when using the data with models, which deterministically transform weather data into plant growth and into exchange fluxes of matter and energy.

Several breaks can easily be identified from graphical visualizations of the data. Figure 7a shows a shift in air pressure measured in Selhausen from 2009 to 2010 using different instruments. A similar effect can be observed in the Merzenhausen data. Figure $7 \mathrm{~b}$ illustrates different maxima of relative humidity in 2015 in Hürtgenwald, which are due to differences in instrument calibration. This effect can also be found in the data for Merzenhausen and Selhausen. Other obvious breaks refer to lower extrema of air temperature (SE and ME), maxima of global radiation (ME), maxima of wind speed (SE), and changing temporal variability of wind speed (HW). Often, these breaks coincide with a change in the main source station (Table 10). Other less noticeable breaks may be included in the time series.

The removal of such breaks in the time series is known in the literature as homogenization. Several methods have been developed to detect the breaks and correct for inconsistencies. However, most of these methods were designed for monthly or annual data (Venema et al., 2012) and are not applicable to subdaily data (Aguilar et al., 2003; Auer et al., 2005; Wijngaard et al., 2003). Since methods for data on higher temporal resolutions would involve dealing with nonlinear atmospheric processes (Della-Marta and Wanner, 2006), the World Meteorological Organization does not yet make any recommendations on how to homogenize these data. Nevertheless, the following literature might help in finding an appropriate homogenization method for the intended application of the data: Vincent et al. (2002), Brandsma and Können (2006), Della-Marta and Wanner (2006), Kuglitsch et al. (2009), Mestre et al. (2011), and Trewin (2013) for temperature; Beaulieu et al. (2008), and Beaulieu et al. (2009) for precipitation; and Domonkos and Coll (2017) for both.

\subsection{Quality assurance}

Time series of meteorological data were checked for plausibility of the recorded data. Values outside of a plausible range were removed from the dataset. Periods of repeated identical (but plausible) values were removed. To ensure good quality of gap filling, the gap-filling methods were applied to periods with measurements of good quality. 
(a) Selhausen

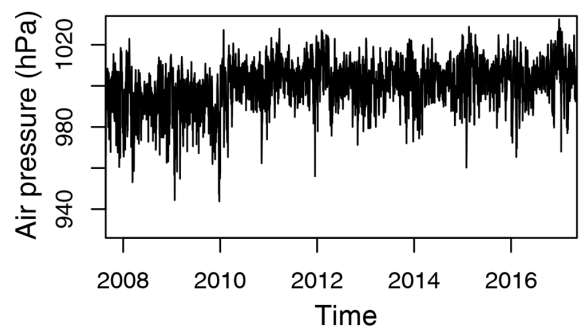

(b) Hürtgenwald

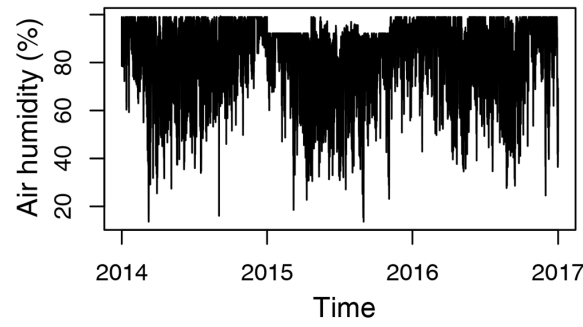

Figure 7. Breaks in time series of meteorological measurements. (a) Air pressure in Selhausen, (b) air humidity in Hürtgenwald.

Table 11. Instrument uncertainties for meteorological measurements at stations 1 to 21 and 25 (for station IDs see Table 9).

\begin{tabular}{|c|c|}
\hline Variable & Uncertainty \\
\hline Air pressure $(\mathrm{Pa})$ & $\begin{array}{l}\text { p_ref (flux data): } 1 \% \text { for relative humidity } \\
\text { AirPres (weather data): } 0 \text { to } 30^{\circ} \mathrm{C}: \pm 0.5 \mathrm{hPa} ;-52 \text { to }+60{ }^{\circ} \mathrm{C} \text { : } \\
\pm 1 \mathrm{hPa}\end{array}$ \\
\hline Global radiation $\left(\mathrm{W} \mathrm{m}^{-2}\right)$ & $\pm 5 \%$ to $\pm 10 \%$ for daily sums \\
\hline Air temperature $\left({ }^{\circ} \mathrm{C}\right)$ & $\pm 0.2-0.4^{\circ} \mathrm{C}$ \\
\hline Air humidity (\%) & $\begin{array}{l}\text { Accuracy at } 20^{\circ} \mathrm{C} \text { : } \\
\pm 2 \% \mathrm{RH}(0 \% \text { to } 90 \% \text { relative humidity); } \pm 3 \% \mathrm{RH}(90 \% \text { to } \\
100 \% \text { relative humidity) }\end{array}$ \\
\hline Wind speed $\left(\mathrm{m} \mathrm{s}^{-1}\right)$ & $\begin{array}{l}\text { Offset error: } \\
< \pm 8.0 \mathrm{~cm} \mathrm{~s}^{-1}(u, v),< \pm 4.0 \mathrm{~cm} \mathrm{~s}^{-1}(z) \\
\text { Gain error: } \\
\text { Wind vector within } \pm 5^{\circ} \text { of horizontal: }< \pm 2 \% \text { of reading } \\
\text { Wind vector within } \pm 10^{\circ} \text { of horizontal: }< \pm 3 \% \text { of reading } \\
\text { Wind vector within } \pm 20^{\circ} \text { of horizontal: }< \pm 6 \% \text { of reading }\end{array}$ \\
\hline Precipitation $\left(\mathrm{mm} \mathrm{h}^{-1}\right)$ & $<3 \%$ \\
\hline Cloudiness $(1 / 8)$ & Uncertainty unknown \\
\hline Wind direction $\left({ }^{\circ}\right)^{*}$ & $\pm 0.7^{\circ}$ at $1 \mathrm{~m} \mathrm{~s}^{-1}$ for horizontal wind \\
\hline
\end{tabular}

* Included in flux data files.

\subsection{Uncertainty}

Measurement uncertainties of weather variables are given as instrument errors in Table 11. It has to be mentioned that especially for precipitation, the instrument error is much smaller than systematic errors. For a discussion of such errors, see Dengel et al. (2018).

Additional uncertainty occurs when gaps in time series are filled based on data from other stations. Because different methods and data sources were used, uncertainty was determined separately for the different sites and years. For the years 2007 to 2010 , uncertainty was estimated by deriving a fill value from remote stations for each available value at the reference station using the respective method shown in Table 10. Bias and root mean square error (RMSE) were calculated from the differences (Table 12). These results for the
Selhausen site are assumed to be transferable to the other sites.

For the EOF method, which was applied for the years from 2011 to 2017, an extra run on a dataset copy with artificial gaps was used to determine worst-case uncertainty estimates. These artificial gaps were inserted for the Merzenhausen site for the 2.5 consecutive days with the highest mean for the respective variable (relative humidity: lowest mean) for all sensors at the site. The artificial gaps were then filled, and the differences to the measured data were evaluated in terms of bias and RMSE (Table 12). By selecting an extreme situation for gap filling, uncertainties for the EOF method are a worstcase estimate. Inserting arbitrary gaps would probably give lower uncertainty values. In addition to this, when comparing uncertainty estimates between different periods, it has to be taken into account that the analysis for the EOF method was 
Table 12. Uncertainty estimates for weather time series gap filling expressed as pairs of bias $(B)$ and RMSE $(R)$. Missing data are denoted by NA; "-" marks cases where there were no gaps or no data. Methods are described in the text. For abbreviations see Table A7.

\begin{tabular}{|c|c|c|c|c|c|c|c|c|c|c|c|c|c|c|}
\hline \multirow[t]{2}{*}{ Period } & \multicolumn{2}{|c|}{ AirPres (Pa) } & \multicolumn{2}{|c|}{ GlobRad $\left(\mathrm{W} \mathrm{m}^{-2}\right)$} & \multicolumn{2}{|c|}{ AirTemp (K) } & \multicolumn{2}{|c|}{ AirHum (\%) } & \multicolumn{2}{|c|}{ Wind $\left(\mathrm{m} \mathrm{s}^{-1}\right)$} & \multicolumn{2}{|c|}{ Precip (mm) } & \multicolumn{2}{|c|}{$\operatorname{InLW}\left(\mathrm{W} \mathrm{m}^{-2}\right)$} \\
\hline & $B$ & $R$ & $B$ & $R$ & $B$ & $R$ & $B$ & $R$ & $B$ & $R$ & $B$ & $R$ & $B$ & $R$ \\
\hline $2007-2009$ & 24.7 & 27.2 & - & - & 0.1 & 0.9 & -5.7 & 9.5 & -0.4 & 0.9 & NA & NA & - & - \\
\hline 2010 & - & - & NA & NA & -0.3 & 0.8 & -5.7 & 8.0 & 0.1 & 0.8 & NA & NA & - & - \\
\hline 2011-2017 & -7.6 & 12.2 & 0.6 & 78.8 & 0.1 & 0.9 & 0.3 & 1.2 & -1.6 & 2.5 & -0.1 & 0.3 & -5.8 & 24.6 \\
\hline
\end{tabular}

applied to raw $10 \mathrm{~min}$ data, while the evaluation for the years 2007 to 2010 is based on hourly data, which generally results in slightly lower RMSE values. Again, we assume that results can be transferred to the Selhausen site.

For precipitation in the period 2007 to 2010 and for global radiation in 2010, uncertainty estimates cannot be given since the raw data are no longer available. Data from the German Meteorological Service (DWD) were used for global radiation in 2007 to 2009 and for air pressure in 2010. Since these data were without gaps, there is no gap-filling uncertainty for these variables.

\subsection{Data format}

Weather data are provided in a UTF-8-coded CSV file per site named "meteo_" followed by the two-letter site abbreviation (Table 2) and the span of years available. The column separator is the semicolon (;). A description of columns and units is presented in Table A7. The no-data symbol is NA. The files have two header lines, of which the first contains the variable names, while the second contains the units.

\section{Crop management data}

\subsection{Data source and methods}

Crop management data were obtained from the farmers by means of a questionnaire. However, the information given by the farmers was only reported for 27 out of 58 management periods and is often incomplete (Table 3). The following information was inquired:

- sowing date

- sowing density, row spacing, seed spacing in a row, seed weight, sowing depth, cultivar

- fertilization date, amount, and product

- cultivation date and type

- growth regulator application date, amount, and product

- fungicide/insecticide/herbicide application date, amount, and product
- harvesting date

- dry weight of yield after harvest

- information on residues left on the field

All fertilization data were recalculated to kilograms of nitrogen per hectare. Since for some products, nitrogen content is not explicitly stated, the following assumptions were made: it was assumed that KAS (calcium ammonium nitrate) contains 27 mass \% nitrogen. Furthermore, it was assumed that sulfane contains 24 mass \% nitrogen. AHL (urea ammonium nitrate solution, UAN) was assumed to have a density of $1.3 \mathrm{~kg} \mathrm{~L}^{-1}$. All fields were managed conventionally.

Applications of the management data can be found in Korres et al. (2013) or Schmidt et al. (2012).

\subsection{Quality assurance}

Some of the fields were equipped with automatic camera systems, which took hourly photos. Management information gathered from the farmers was checked against these photos.

\subsection{Uncertainty}

Accuracy of management data is based on the reliability of the information provided by the farmers. Since there is no way to check information on fertilizer or agrochemical types and amounts, an uncertainty cannot be assigned.

\subsection{Data format}

Management data are provided in a UTF-8-coded CSV file per management period. The file name starts with "management_" followed by the ID of the management period (e.g., management_SEF08WW09.txt). The file can contain data on management activities in the fallow period before or after harvest. If no management information is available, the file contains a comment only. There are no management files for management periods denominated "harvest residues" (HR).

Each record is structured in the same way: date; keyword; additional information. The elements of the record are separated by a semicolon (;). The record starts with the date in YYYY-MM-DD format, where day may be replaced by " $x x$ " if the exact date is unknown. In the second position, the 
record contains a keyword that defines the management activity. Keywords refer to basic crop-related activities ("Sowing", "Harvesting", "Fertilizer", "Cutting"), soil management ("Plow", "Rotary harrow", "Harrow", "Roller", "Cultivator", "Tire packer"), and application of agrochemicals ("Herbicide", "Growth control", "Fungicide", "Insecticide", "Coformulant"). After the keyword, one or more pieces of additional information may follow in a semicolon-separated list.

- Fertilizer: amount of fertilizer in kilograms of nitrogen per hectare, information on the product and its contents (may also be a semicolon-separated list)

- Application of agrochemicals: amount of agrochemical per area, information on the product and its contents (may also be a semicolon-separated list)

- Sowing: sowing density, row spacing, seed spacing, weight of seeds, sowing depth, cultivar

Unknown information is indicated by the no-data symbol NA. Units are given with the data. Comments start with “\#”. Comments can contain additional information on yield, management of harvest residues, additional contents of agrochemicals, etc.

\section{Data availability}

The dataset can be downloaded from the TR32 database (https://www.tr32db.uni-koeln.de/data.php?dataID=1889, last access: 29 September 2020) or using the DOI https://doi.org/10.5880/TR32DB.39 (Reichenau et al., 2020). The dataset is provided as a zip-compressed container. All files are plain text files organized in a folder per site as shown in Fig. 2 and as explained in Sect. 3. Technical details on file formats and data structure within files are presented for the different kinds of data in Sects. 4.4, 5.4, 6.4, 7.4, and 8.4. 


\section{Appendix A}

The tables in the appendix describe the data files in terms of their column order, variables, units, and data types (Tables A1-A3, A5-A7) and specify soil particle size classes (Table A4).

Table A1. Columns in the vegetation data files.

\begin{tabular}{|c|c|c|c|c|}
\hline $\begin{array}{l}\text { Col. } \\
\text { no. }\end{array}$ & Variable & Units & Data type & Description \\
\hline 1 & dataset & - & Character & Dataset name \\
\hline 2 & test_site & - & Character & Site ID \\
\hline 3 & field & - & Character & Field ID (per site) \\
\hline 4 & land_use & - & Character & Land use ID \\
\hline 5 & Date & - & Date & Date of field measurement (YYYY-MM-DD) \\
\hline 6 & time & - & Time & UTC time of field measurement (hh:mm) \\
\hline 7 & UTM_northing & $\mathrm{m}$ & Numeric & UTM northing (WGS 1984, 32N) \\
\hline 8 & UTM_northing_FLAG & - & Numeric & UTM northing quality flag \\
\hline 9 & UTM_easting & $\mathrm{m}$ & Numeric & UTM easting (WGS 1984, 32N) \\
\hline 10 & UTM_easting_FLAG & - & Numeric & UTM easting quality flag \\
\hline 11 & canopy_height & $\mathrm{cm}$ & Numeric & Height of the canopy \\
\hline 12 & bbch & $\mathrm{BBCH}^{*}$ & Character & Phenological development state (BBCH scale) \\
\hline 13 & num_plants_m2 & $\mathrm{m}^{-2}$ & Numeric & Number of plants per square meter (calculated) \\
\hline 14 & LAI_green & $\mathrm{m}^{2} \mathrm{~m}^{-2}$ & Numeric & Green LAI \\
\hline 15 & LAI_green_FLAG & - & Numeric & Green LAI quality flag \\
\hline 16 & LAI_brown & $\mathrm{m}^{2} \mathrm{~m}^{-2}$ & Numeric & Brown LAI \\
\hline 17 & LAI_brown_FLAG & - & Numeric & Brown LAI quality flag \\
\hline 18 & FW_green_leaves & $\mathrm{g} \mathrm{m}^{-2}$ & Numeric & Fresh weight of green leaves \\
\hline 19 & FW_green_leaves_FLAG & - & Numeric & Fresh weight of green leaves quality flag \\
\hline 20 & DW_green_leaves & $\mathrm{g} \mathrm{m}^{-2}$ & Numeric & Dry weight of green leaves \\
\hline 21 & DW_green_leaves_FLAG & - & Numeric & Dry weight of green leaves quality flag \\
\hline 22 & FW_brown_leaves & $\mathrm{g} \mathrm{m}^{-2}$ & Numeric & Fresh weight of brown leaves \\
\hline 23 & FW_brown_leaves_FLAG & - & Numeric & Fresh weight of brown leaves quality flag \\
\hline 24 & DW_brown_leaves & $\mathrm{g} \mathrm{m}^{-2}$ & Numeric & Dry weight of brown leaves \\
\hline 25 & DW_brown_leaves_FLAG & - & Numeric & Dry weight of brown leaves quality flag \\
\hline 26 & FW_green_stems & $\mathrm{g} \mathrm{m}^{-2}$ & Numeric & Fresh weight of green stems/tillers/stalks \\
\hline 27 & FW_green_stems_FLAG & - & Numeric & Fresh weight of green stems/tillers/stalks quality flag \\
\hline 28 & DW_green_stems & $\mathrm{g} \mathrm{m}^{-2}$ & Numeric & Dry weight of green stems/tillers/stalks \\
\hline 29 & DW_green_stems_FLAG & - & Numeric & Dry weight of green stems/tillers/stalks quality flag \\
\hline 30 & FW_brown_stems & $\mathrm{g} \mathrm{m}^{-2}$ & Numeric & Fresh weight of brown stems/tillers/stalks \\
\hline 31 & FW_brown_stems_FLAG & - & Numeric & Fresh weight of brown stems/tillers/stalks quality flag \\
\hline 32 & DW_brown_stems & $\mathrm{g} \mathrm{m}^{-2}$ & Numeric & Dry weight of brown stems/tillers/stalks \\
\hline 33 & DW_brown_stems_FLAG & - & Numeric & Dry weight of brown stems/tillers/stalks quality flag \\
\hline 34 & FW_fruit & $\mathrm{g} \mathrm{m}^{-2}$ & Numeric & Fresh weight of harvest organ (e.g., fruit, beet) \\
\hline 35 & FW_fruit_FLAG & - & Numeric & Fresh weight of harvest organ quality flag \\
\hline 36 & DW_fruit & $\mathrm{g} \mathrm{m}^{-2}$ & Numeric & Dry weight of harvest organ (e.g., fruit, beet) \\
\hline 37 & DW_fruit_FLAG & - & Numeric & Dry weight of harvest organ quality flag \\
\hline 38 & FW_biomass_undiff & $\mathrm{g} \mathrm{m}^{-2}$ & Numeric & Fresh weight of aboveground biomass not separated into organs \\
\hline 39 & FW_biomass_undiff_FLAG & - & Numeric & $\begin{array}{l}\text { Fresh weight of aboveground biomass not separated into organs } \\
\text { quality flag }\end{array}$ \\
\hline
\end{tabular}


Table A1. Continued.

\begin{tabular}{|c|c|c|c|c|}
\hline $\begin{array}{l}\text { Col. } \\
\text { no. }\end{array}$ & Variable & Units & Data type & Description \\
\hline 40 & DW_biomass_undiff & $\mathrm{g} \mathrm{m}^{-2}$ & Numeric & Dry weight of aboveground biomass not separated into organs \\
\hline 41 & DW_biomass_undiff_FLAG & - & Numeric & $\begin{array}{l}\text { Dry weight of aboveground biomass not separated into organs } \\
\text { quality flag }\end{array}$ \\
\hline 42 & FW_harvest_residues & $\mathrm{g} \mathrm{m}^{-2}$ & Numeric & Fresh weight of harvest residues \\
\hline 43 & FW_harvest_residues_FLAG & - & Numeric & Fresh weight of harvest residues quality flag \\
\hline 44 & DW_harvest_residues & $\mathrm{g} \mathrm{m}^{-2}$ & Numeric & Dry weight of harvest residues \\
\hline 45 & DW_harvest_residues_FLAG & - & Numeric & Dry weight of harvest residues quality flag \\
\hline 46 & FW_green_sprouts & $\mathrm{g} \mathrm{m}^{-2}$ & Numeric & Fresh weight of green sprouts (growing between harvest residues) \\
\hline 47 & FW_green_sprouts_FLAG & - & Numeric & Fresh weight of green sprouts quality flag \\
\hline 48 & DW_green_sprouts & $\mathrm{g} \mathrm{m}^{-2}$ & Numeric & Dry weight of green sprouts (growing between harvest residues) \\
\hline 49 & DW_green_sprouts_FLAG & - & Numeric & Dry weight of green sprouts quality flag \\
\hline 50 & FW_other & $\mathrm{g} \mathrm{m}^{-2}$ & Numeric & Fresh weight of other biomass (e.g., weeds) \\
\hline 51 & FW_other_FLAG & - & Numeric & Fresh weight of other biomass quality flag \\
\hline 52 & DW_other & $\mathrm{g} \mathrm{m}^{-2}$ & Numeric & Dry weight of other biomass (e.g., weeds) \\
\hline 53 & DW_other_FLAG & - & Numeric & Dry weight of other biomass quality flag \\
\hline 54 & other_descr & - & Character & Type of biomass measured as "biomass_other" \\
\hline 55 & N_green_leaves & $\operatorname{mass} \%$ & Numeric & Relative nitrogen content of green leaves \\
\hline 56 & C_green_leaves & $\operatorname{mass} \%$ & Numeric & Relative carbon content of green leaves \\
\hline 57 & N_brown_leaves & $\operatorname{mass} \%$ & Numeric & Relative nitrogen content of brown leaves \\
\hline 58 & C_brown_leaves & $\operatorname{mass} \%$ & Numeric & Relative carbon content of brown leaves \\
\hline 59 & N_green_stems & $\operatorname{mass} \%$ & Numeric & Relative nitrogen content of green stems/tillers/stalks \\
\hline 60 & C_green_stems & $\operatorname{mass} \%$ & Numeric & Relative carbon content of green stems/tillers/stalks \\
\hline 61 & N_brown_stems & $\operatorname{mass} \%$ & Numeric & Relative nitrogen content of brown stems/tillers/stalks \\
\hline 62 & C_brown_stems & $\operatorname{mass} \%$ & Numeric & Relative carbon content of brown stems/tillers/stalks \\
\hline 63 & N_fruit & $\operatorname{mass} \%$ & Numeric & Relative nitrogen content of harvest organ (e.g., fruit, beet) \\
\hline 64 & C_fruit & $\operatorname{mass} \%$ & Numeric & Relative carbon content of harvest organ (e.g., fruit, beet) \\
\hline 65 & N_biomass_undiff & $\operatorname{mass} \%$ & Numeric & $\begin{array}{l}\text { Relative nitrogen content of aboveground biomass not separated into } \\
\text { organs }\end{array}$ \\
\hline 66 & C_biomass_undiff & $\operatorname{mass} \%$ & Numeric & $\begin{array}{l}\text { Relative carbon content of aboveground biomass not separated into } \\
\text { organs }\end{array}$ \\
\hline 67 & N_harvest_residues & $\operatorname{mass} \%$ & Numeric & Relative nitrogen content of harvest residues \\
\hline 68 & C_harvest_residues & $\operatorname{mass} \%$ & Numeric & Relative carbon content of harvest residues \\
\hline 69 & N_green_sprouts & $\operatorname{mass} \%$ & Numeric & $\begin{array}{l}\text { Relative nitrogen content of green sprouts (growing between harvest } \\
\text { residues) }\end{array}$ \\
\hline 70 & C_green_sprouts & mass $\%$ & Numeric & $\begin{array}{l}\text { Relative carbon content of green sprouts (growing between harvest } \\
\text { residues) }\end{array}$ \\
\hline 71 & N_other & $\operatorname{mass} \%$ & Numeric & Relative nitrogen content of other biomass (e.g., weeds) \\
\hline 72 & C_other & $\operatorname{mass} \%$ & Numeric & Relative carbon content of other biomass (e.g., weeds) \\
\hline 73 & is_cn_field_mean & - & Logical & $\begin{array}{l}\text { Has } \mathrm{C} \text { and } \mathrm{N} \text { content been measured from a composite sampled from } \\
\text { all points in the field? }\end{array}$ \\
\hline 74 & soil_unit & - & Character & Assignment to a soil unit of Brogi et al. (2019), only Selhausen \\
\hline 75 & comment & - & Character & Comment \\
\hline
\end{tabular}

* See Meier et al. (2009) and references therein. 
Table A2. Columns of flux data files processed with the software ECpack. With the exception of the timestamps, all data types are numeric.

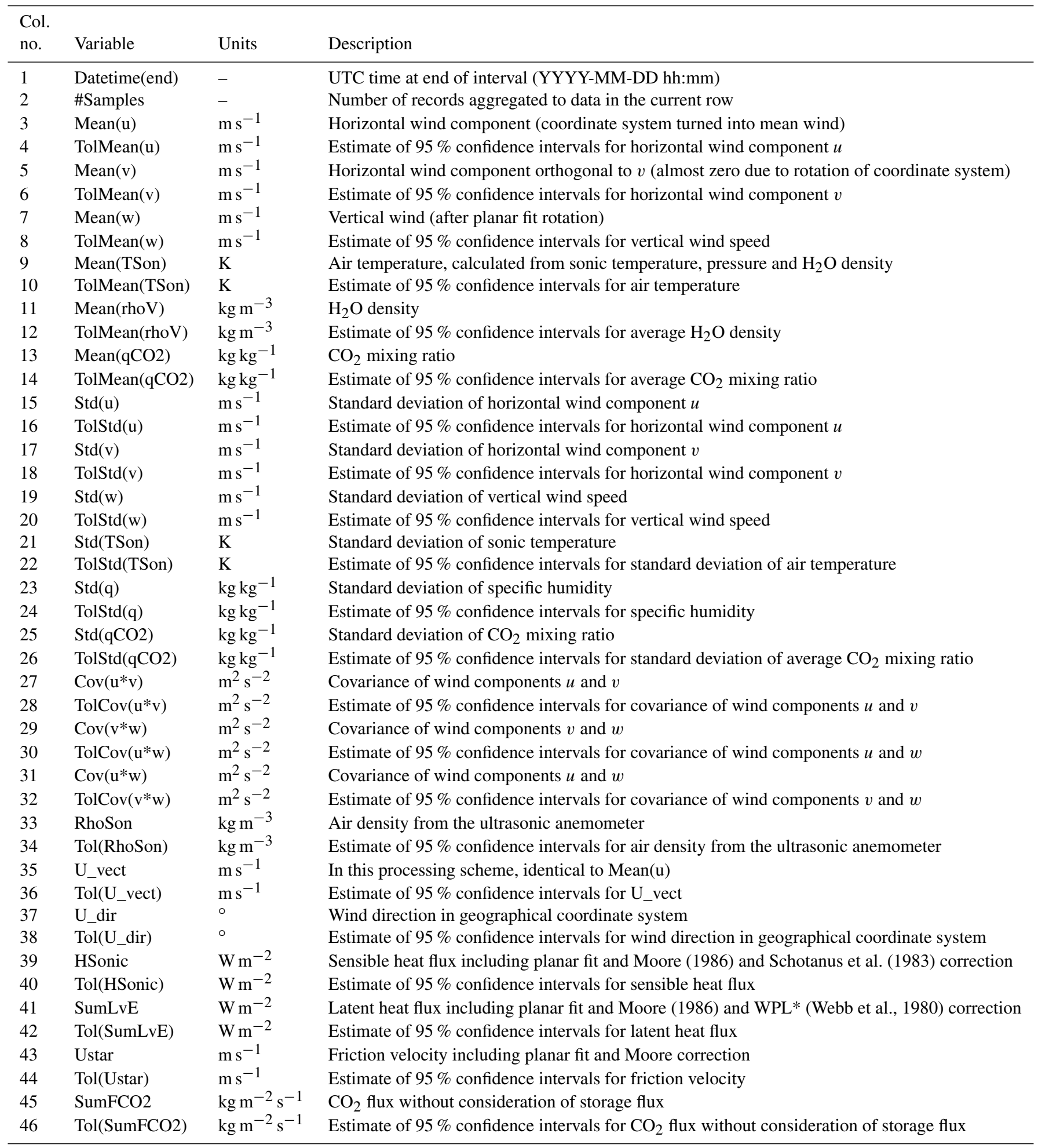

* The WPL correction is named after the first letters of the surnames of the authors of Webb et al. (1980). 
Table A3. Columns of flux data files processed with the software TK. With the exception of the timestamps, all data types are numeric.

\begin{tabular}{|c|c|c|c|}
\hline $\begin{array}{l}\text { Col. } \\
\text { no. }\end{array}$ & Variable & Units & Description \\
\hline 1 & T_begin & - & UTC time at beginning of interval (YYYY-MM-DD hh:mm) \\
\hline 2 & T_end & - & UTC time at end of interval (YYYY-MM-DD hh:mm) \\
\hline 3 & $\mathrm{u}$ & $\mathrm{ms}^{-1}$ & Horizontal wind speed (coordinate system turned into mean wind) \\
\hline 4 & $\mathrm{v}$ & $\mathrm{ms}^{-1}$ & Horizontal wind speed (zero due to rotation of coordinate system) \\
\hline 5 & $\mathrm{w}$ & $\mathrm{m} \mathrm{s}^{-1}$ & Vertical wind speed \\
\hline 6 & Ts & ${ }^{\circ} \mathrm{C}$ & Sonic temperature \\
\hline 7 & $\mathrm{Tp}$ & ${ }^{\circ} \mathrm{C}$ & (No data) \\
\hline 8 & $\mathrm{a}$ & $\mathrm{g} \mathrm{m}^{-3}$ & $\mathrm{H}_{2} \mathrm{O}$ content of the air (LI7500) \\
\hline 9 & $\mathrm{CO} 2$ & $\mathrm{mmol} \mathrm{m}^{-3}$ & $\mathrm{CO}_{2}$ content of the air \\
\hline 10 & T_ref & ${ }^{\circ} \mathrm{C}$ & Air temperature \\
\hline 11 & a_ref & $\mathrm{g} \mathrm{m}^{-3}$ & Reference $\mathrm{H}_{2} \mathrm{O}$ content of the air (HMP45C) \\
\hline 12 & p_ref & $\mathrm{hPa}$ & Air pressure \\
\hline 13 & $\operatorname{Var}[\mathrm{u}]$ & $\mathrm{m}^{2} \mathrm{~s}^{-2}$ & Variance of horizontal wind speed \\
\hline 14 & $\operatorname{Var}[\mathrm{v}]$ & $\mathrm{m}^{2} \mathrm{~s}^{-2}$ & Variance of horizontal wind speed \\
\hline 15 & $\operatorname{Var}[w]$ & $\mathrm{m}^{2} \mathrm{~s}^{-2}$ & Variance of vertical wind speed \\
\hline 16 & $\operatorname{Var}[\mathrm{Ts}]$ & ${ }^{\circ} \mathrm{C}^{-2}$ & Variance of sonic temperature \\
\hline 17 & $\operatorname{Var}[\mathrm{Tp}]$ & ${ }^{\circ} \mathrm{C}^{-2}$ & (No data) \\
\hline 18 & $\operatorname{Var}[\mathrm{a}]$ & $\mathrm{g}^{2} \mathrm{~m}^{-6}$ & Variance of $\mathrm{H}_{2} \mathrm{O}$ content of the air \\
\hline 19 & $\operatorname{Var}[\mathrm{CO} 2]$ & $\mathrm{mmol}^{2} \mathrm{~m}^{-6}$ & Variance of $\mathrm{CO}_{2}$ content of the air \\
\hline 20 & Cov[u'v'] & $\mathrm{m}^{2} \mathrm{~s}^{-2}$ & Covariance of wind components $u$ and $v$ \\
\hline 21 & $\operatorname{Cov}\left[v^{\prime} w^{\prime}\right]$ & $\mathrm{m}^{2} \mathrm{~s}^{-2}$ & Covariance of wind components $v$ and $w$ \\
\hline 22 & $\operatorname{Cov}\left[u^{\prime} w '\right]$ & $\mathrm{m}^{2} \mathrm{~s}^{-2}$ & Covariance of wind components $u$ and $w$ \\
\hline 23 & $\operatorname{Cov}\left[u^{\prime} T s^{\prime}\right]$ & ${ }^{\circ} \mathrm{C} \mathrm{m} \mathrm{s}^{-1}$ & Covariance of wind component $u$ and sonic temperature \\
\hline 24 & Cov[v'Ts'] & ${ }^{\circ} \mathrm{C} \mathrm{m} \mathrm{s}^{-1}$ & Covariance of wind component $v$ and sonic temperature \\
\hline 25 & $\operatorname{Cov}\left[w^{\prime} T s^{\prime}\right]$ & ${ }^{\circ} \mathrm{C} \mathrm{m} \mathrm{s}^{-1}$ & Covariance of wind component $w$ and sonic temperature \\
\hline 26 & $\operatorname{Cov}\left[\mathrm{u}^{\prime} \mathrm{T}\right.$ '] $]$ & ${ }^{\circ} \mathrm{C} \mathrm{m} \mathrm{s}^{-1}$ & (No data) \\
\hline 27 & Cov[v'Tp'] & ${ }^{\circ} \mathrm{C} \mathrm{m} \mathrm{s}^{-1}$ & (No data) \\
\hline 28 & $\operatorname{Cov}[w ' T p ']$ & ${ }^{\circ} \mathrm{C} \mathrm{m} \mathrm{s}{ }^{-1}$ & (No data) \\
\hline 29 & Cov[u'a'] & $\mathrm{g} \mathrm{s}^{-1} \mathrm{~m}^{-2}$ & Covariance of wind component $u$ and $\mathrm{H}_{2} \mathrm{O}$ content of the air \\
\hline 30 & Cov[v'a'] & $\mathrm{g} \mathrm{s}^{-1} \mathrm{~m}^{-2}$ & Covariance of wind component $v$ and $\mathrm{H}_{2} \mathrm{O}$ content of the air \\
\hline 31 & Cov[w'a'] & $\mathrm{g} \mathrm{s}^{-1} \mathrm{~m}^{-2}$ & Covariance of wind component $w$ and $\mathrm{H}_{2} \mathrm{O}$ content of the air \\
\hline 32 & $\operatorname{Cov}\left[\mathrm{u}^{\prime} \mathrm{CO} 2^{\prime}\right]$ & $\mathrm{mmol} \mathrm{m}^{-2} \mathrm{~s}^{-1}$ & Covariance of wind component $u$ and $\mathrm{CO}_{2}$ content of the air \\
\hline 33 & $\operatorname{Cov}\left[v^{\prime} \mathrm{CO} 2^{\prime}\right]$ & $\mathrm{mmol} \mathrm{m}^{-2} \mathrm{~s}^{-1}$ & Covariance of wind component $v$ and $\mathrm{CO}_{2}$ content of the air \\
\hline 34 & $\mathrm{Cov}\left[\mathrm{w}^{\prime} \mathrm{CO} 2^{\prime}\right]$ & $\mathrm{mmol} \mathrm{m}^{-2} \mathrm{~s}^{-1}$ & Covariance of wind component $w$ and $\mathrm{CO}_{2}$ content of the air \\
\hline 35 & Nvalue & - & Number of samples the aggregated 30 min value is based on \\
\hline 36 & $\operatorname{dir}$ & $\circ$ & Wind direction \\
\hline 37 & ustar & $\mathrm{ms}^{-1}$ & Friction velocity \\
\hline 38 & HTs & $\mathrm{W} \mathrm{m}^{-2}$ & Sensible heat flux \\
\hline 39 & HTp & $\mathrm{W} \mathrm{m}^{-2}$ & (No data) \\
\hline 40 & LvE & $\mathrm{W} \mathrm{m}^{-2}$ & Latent heat flux \\
\hline 41 & $\mathrm{z} / \mathrm{L}$ & - & $\begin{array}{l}\text { Stability parameter (positive values denote stable boundary layer) based on sonic tem- } \\
\text { perature }\end{array}$ \\
\hline 42 & z/L-virt & - & $\begin{array}{l}\text { Stability parameter (positive values denote stable boundary layer) based on virtual tem- } \\
\text { perature }\end{array}$ \\
\hline 43 & Flag(ustar) & - & Quality flag for ustar time series (refer to the flag info in the "general info" sheet) \\
\hline 44 & Flag(HTs) & - & $\begin{array}{l}\text { Quality flag for sensible heat time series (refer to the flag info in the "general info" } \\
\text { sheet) }\end{array}$ \\
\hline 45 & Flag(HTp) & - & (No data) \\
\hline 46 & Flag(LvE) & - & Quality flag for latent heat time series (refer to the flag info in the "general info" sheet) \\
\hline 47 & Flag(wCO2) & - & Quality flag for NEE time series (refer to the flag info in the "general info" sheet) \\
\hline 48 & T_mid & - & UTC time at middle of interval (YYYY-MM-DD hh:mm) \\
\hline 49 & FCstor & $\mathrm{mmol} \mathrm{m}^{-2} \mathrm{~s}^{-1}$ & $\mathrm{CO}_{2}$ storage of the air column below the measurement height \\
\hline
\end{tabular}


Table A3. Continued.

\begin{tabular}{|c|c|c|c|}
\hline $\begin{array}{l}\text { Col. } \\
\text { no. }\end{array}$ & Variable & Units & Description \\
\hline 50 & NEE & $\mathrm{mmol} \mathrm{m} \mathrm{m}^{-2} \mathrm{~s}^{-1}$ & Net ecosystem exchange of $\mathrm{CO}_{2}$ \\
\hline 51 & Ftprint_trgt_1 & $\%$ & Cumulative source contribution of the target area \\
\hline 52 & Ftprint_trgt_2 & $\%$ & Cumulative source contribution of adjacent areas of the same type as the target area \\
\hline 53 & Ftprnt_xmax & $\mathrm{m}$ & Distance between EC tower and the point of the maximum source contribution \\
\hline 54 & r_err_ustar & $\%$ & Relative random error of ustar \\
\hline 55 & r_err_HTs & $\%$ & Relative random error of HTs \\
\hline 56 & r_err_LvE & $\%$ & Relative random error of $\mathrm{LvE}$ \\
\hline 57 & r_err_co2 & $\%$ & Relative random error of $\mathrm{CO}_{2}$ flux \\
\hline 58 & noise_ustar & $\%$ & Relative noise error of ustar \\
\hline 59 & noise_HTs & $\%$ & Relative noise error of HTs \\
\hline 60 & noise_LvE & $\%$ & Relative noise error of $\mathrm{LvE}$ \\
\hline 61 & noise_co2 & $\%$ & Relative noise error of $\mathrm{CO}_{2}$ flux \\
\hline
\end{tabular}


Table A4. Size ranges of particle size classes (DIN 14688).

\begin{tabular}{llr}
\hline $\begin{array}{l}\text { Particle } \\
\text { size class }\end{array}$ & Abbreviation & $\begin{array}{r}\text { Size } \\
\text { range }(\mathrm{mm})\end{array}$ \\
\hline Coarse material/gravel & $\mathrm{Gr}$ & $>2$ \\
Coarse sand & $\mathrm{CSa}$ & $0.63-2$ \\
Medium sand & $\mathrm{MSa}$ & $0.2-0.63$ \\
Fine sand & $\mathrm{FSa}$ & $0.063-0.2$ \\
Sand & $\mathrm{Sa}$ & $0.063-2$ \\
Coarse silt & $\mathrm{CSi}$ & $0.02-0.063$ \\
Medium silt & $\mathrm{MSi}$ & $0.0063-0.02$ \\
Fine silt & $\mathrm{FSi}$ & $0.002-0.0063$ \\
Silt & $\mathrm{Si}$ & $0.002-0.063$ \\
Clay & $\mathrm{Cl}$ & $\leq 0.002$ \\
\hline
\end{tabular}


Table A5. Columns of soil data files. For particle size classes see Table A4.

\begin{tabular}{|c|c|c|c|c|}
\hline Col. no. & Variable & Units & Data type & Description \\
\hline 1 & Site & - & Character & Site ID \\
\hline 2 & Field & - & Character & Field ID (per site) \\
\hline 3 & UTM_northing & $\mathrm{m}$ & Numeric & UTM northing (WGS 1984, 32N) \\
\hline 4 & UTM_easting & $\mathrm{m}$ & Numeric & UTM easting (WGS 1984, 32N) \\
\hline 5 & Depth & $\mathrm{cm}$ & Character & Sampling depth (layer) \\
\hline 6 & horizon & - & Character & Soil horizon (see Schad et al., 2009) \\
\hline 7 & $\mathrm{CSa}$ & $\operatorname{mass} \%$ & Numeric & Percentage of coarse sand particles in fine soil \\
\hline 8 & MSa & mass $\%$ & Numeric & Percentage of medium sand particles in fine soil \\
\hline 9 & $\mathrm{FSa}$ & mass $\%$ & Numeric & Percentage of fine sand particles in fine soil \\
\hline 10 & $\mathrm{Sa}$ & mass $\%$ & Numeric & Percentage of sand particles in fine soil $(\mathrm{CSa}+\mathrm{MSa}+\mathrm{FSa})$ \\
\hline 11 & $\mathrm{CSi}$ & mass $\%$ & Numeric & Percentage of coarse silt particles in fine soil \\
\hline 12 & MSi & $\operatorname{mass} \%$ & Numeric & Percentage of medium silt particles in fine soil \\
\hline 13 & FSi & $\operatorname{mass} \%$ & Numeric & Percentage of fine silt particles in fine soil \\
\hline 14 & $\mathrm{Si}$ & mass $\%$ & Numeric & Percentage of silt particles in fine soil $(\mathrm{GSi}+\mathrm{MSi}+\mathrm{FSi})$ \\
\hline 15 & $\mathrm{Cl}$ & mass $\%$ & Numeric & Percentage of clay particles in fine soil \\
\hline 16 & date_part_siz & - & Date and time & Sampling date for particle size distribution (in the field, YYYY-MM-DD) \\
\hline 17 & $\mathrm{Gr}$ & mass $\%$ & Numeric & Percentage of coarse material/gravel in soil sample \\
\hline 18 & bulk_dens & $\mathrm{g} \mathrm{cm}^{-3}$ & Numeric & Bulk density \\
\hline 19 & date_bulk_dens & - & Date and time & Sampling date for bulk density (in the field, YYYY-MM-DD) \\
\hline 20 & SOC & mass $\%$ & Numeric & Soil organic carbon content \\
\hline 21 & tot_C & $\operatorname{mass} \%$ & Numeric & Total carbon content \\
\hline 22 & tot_N & $\operatorname{mass} \%$ & Numeric & Total nitrogen content \\
\hline 23 & date_CN & - & Date and time & Sampling date for $\mathrm{C}$ and $\mathrm{N}$ content (in the field, YYYY-MM-DD) \\
\hline 24 & soil_unit & - & Character & Assignment to a soil unit of Brogi et al. (2019), only Selhausen \\
\hline 25 & comment & - & Character & Comment \\
\hline
\end{tabular}

Table A6. Columns of the soil unit data file. These data exist for the site Selhausen only. For particle size classes see Table A4.

\begin{tabular}{lllll}
\hline Col. no. & Variable & Units & Data type & Description \\
\hline 1 & soil_unit & - & Character & Assignment to a soil unit of Brogi et al. (2019) \\
2 & horizon & - & Character & Soil horizon (see Schad et al., 2009) \\
3 & max_depth & cm & Numeric & Maximum depth of the soil horizon found in the corresponding soil unit \\
4 & Sa & mass $\%$ & Numeric & Percentage of sand particles in fine soil \\
5 & $\mathrm{Si}$ & mass $\%$ & Numeric & Percentage of silt particles in fine soil \\
6 & Cl & mass $\%$ & Numeric & Percentage of clay particles in fine soil \\
7 & Gr & mass $\%$ & Numeric & Percentage of coarse material/gravel in soil sample \\
8 & tot_C & mass $\%$ & Numeric & Total carbon content \\
9 & tot_N & mass $\%$ & Numeric & Total nitrogen content \\
10 & CV_max_depth & $\%$ & Numeric & Uncertainty of max_depth (coefficient of variation) \\
11 & CV_Sa & $\%$ & Numeric & Uncertainty of Sa (coefficient of variation) \\
12 & CV_Si & $\%$ & Numeric & Uncertainty of Si (coefficient of variation) \\
13 & CV_Cl & $\%$ & Numeric & Uncertainty of Cl (coefficient of variation) \\
14 & CV_Gr & $\%$ & Numeric & Uncertainty of Gr (coefficient of variation) \\
\hline
\end{tabular}


Table A7. Columns of weather data files. With the exception of the timestamps, all data types are numeric.

\begin{tabular}{llll}
\hline Col. no. & Variable & Units & Description \\
\hline 1 & Date \& Time begin (UTC) & - & UTC time at beginning of interval (YYYY-MM-DD hh:mm) \\
2 & Date \& Time end (UTC) & - & UTC time at end of interval (YYYY-MM-DD hh:mm) \\
3 & AirPres & $\mathrm{Pa}$ & Air pressure \\
4 & GlobRad & $\mathrm{W} \mathrm{m}^{-2}$ & Global radiation \\
5 & AirTemp & $\mathrm{K}$ & Air temperature \\
6 & AirHum & $\%$ & Relative humidity of the air \\
7 & Wind & $\mathrm{m} \mathrm{s}^{-1}$ & Wind speed \\
8 & Precip & $\mathrm{Mm}$ & Precipitation \\
9 & SurfaceTemp & $\mathrm{K}$ & Surface temperature* \\
10 & InLW & $\mathrm{W} \mathrm{m}{ }^{-2}$ & Incoming longwave radiation \\
11 & Cloudiness & $1 / 8$ & Cloud cover \\
\hline
\end{tabular}

* Contains no data; included for compatibility purposes. 
Author contributions. TR designed and compiled the dataset and did the quality control and processing of the vegetation data. AS and AG did the gap filling of meteorological data and developed the methods. MS and AG were responsible for the eddy covariance data. MS collected the management data. WK, TR, AS, and KS were responsible for the collection of the vegetation data. Meteorological data were acquired by AG, MS, WK, and KS. AG, WK, GW, NM, and CB took and analyzed soil samples. The manuscript was prepared by TR with contributions from all coauthors.

Competing interests. The authors declare that they have no conflict of interest.

Acknowledgements. This study was supported by the Deutsche Forschungsgemeinschaft through the Transregional Collaborative Research Center 32 - Patterns in Soil-Vegetation-Atmosphere Systems: Monitoring, Modeling and Data Assimilation. In addition, support was received through the "Terrestrial ENvironmental Observatories" (TERENO). We thank the numerous student helpers for their help with the field campaigns. Special thanks go to the farmers who granted access to their fields and to our student helpers Michael Holthausen (gap filling of meteorological data), Tobias Bothe (gap filling and soil sampling), and Nils Eingrüber (consistency check of soil data). We thank Florian Steininger for collecting the management data from the farmer in Hürtgenwald, Victor Venema for discussions and literature on the homogenization of meteorological data, Ulrike Schwedler for cartography, and Constanze Curdt for advice concerning all aspects of data management. Finally we want to thank the five reviewers for their helpful comments.

Financial support. This research has been supported by the Deutsche Forschungsgemeinschaft (grant no. TRR 32/3).

Review statement. This paper was edited by Yuyu Zhou and reviewed by four anonymous referees.

\section{References}

Aguilar, E., Auer, I., Brunet, M., Peterson, T. C., and Wieringa, J.: Guidelines on climate metadata and homogenization, WMO/TD No. 1186, Geneva, Switzerland, 2003.

Ahrends, H., Haseneder-Lind, R., Schween, J., Crewell, S., Stadler, A., and Rascher, U.: Diurnal Dynamics of Wheat Evapotranspiration Derived from Ground-Based Thermal Imagery, Remote Sens., 6, 9775-9801, https://doi.org/10.3390/rs6109775, 2014.

Ali, M., Montzka, C., Stadler, A., Menz, G., Thonfeld, F., and Vereecken, H.: Estimation and Validation of RapidEyeBased Time-Series of Leaf Area Index for Winter Wheat in the Rur Catchment (Germany), Remote Sens., 7, 2808-2831, https://doi.org/10.3390/rs70302808, 2015.

Auer, I., Böhm, R., Jurković, A., Orlik, A., Potzmann, R., Schöner, W., Ungersböck, M., Brunetti, M., Nanni, T., Maugeri, M., Briffa, K., Jones, P., Efthymiadis, D., Mestre, O., Moisselin, J.M., Begert, M., Brazdil, R., Bochnicek, O., Cegnar, T., Gajić-
Čapka, M., Zaninović, K., Majstorović, Ž., Szalai, S., Szentimrey, T., and Mercalli, L.: A new instrumental precipitation dataset for the greater alpine region for the period 1800-2002: Precipitation Dataset: European Greater Alpine Region, Int. J. Climatol., 25, 139-166, https://doi.org/10.1002/joc.1135, 2005.

Beaulieu, C., Seidou, O., Ouarda, T. B. M. J., Zhang, X., Boulet, G., and Yagouti, A.: Intercomparison of homogenization techniques for precipitation data: Homogenization of Precipitation, Water Resour. Res., 44, W02425, https://doi.org/10.1029/2006WR005615, 2008.

Beaulieu, C., Seidou, O., Ouarda, T. B. M. J., and Zhang, $\mathrm{X}$.: Intercomparison of homogenization techniques for precipitation data continued: Comparison of two recent Bayesian change point models: Homogenization with Bayesian Change Point, Water Resour. Res., 45, W08410, https://doi.org/10.1029/2008WR007501, 2009.

Beckers, J. M. and Rixen, M.: EOF Calculations and Data Filling from Incomplete Oceanographic Datasets, J. Atmos. Ocean. Tech., 20, 1839-1856, https://doi.org/10.1175/15200426(2003)020<1839:ECADFF> 2.0.CO;2, 2003.

Bogena, H. R.: TERENO: German network of terrestrial environmental observatories, J. Large-Scale Res. Facil. JLSRF, 2, A52, https://doi.org/10.17815/jlsrf-2-98, 2016.

Bornemann, L., Herbst, M., Welp, G., Vereecken, H., and Amelung, W.: Rock Fragments Control Size and Saturation of Organic Carbon Pools in Agricultural Topsoil, Soil Sci. Soc. Am. J., 75, 1898, https://doi.org/10.2136/sssaj2010.0454, 2011.

Brandsma, T. and Können, G. P.: Application of nearestneighbor resampling for homogenizing temperature records on a daily to sub-daily level, Int. J. Climatol., 26, 75-89, https://doi.org/10.1002/joc.1236, 2006.

Brogi, C., Huisman, J. A., Pätzold, S., von Hebel, C., Weihermüller, L., Kaufmann, M. S., van der Kruk, J., and Vereecken, H.: Large-scale soil mapping using multi-configuration EMI and supervised image classification, Geoderma, 335, 133-148, https://doi.org/10.1016/j.geoderma.2018.08.001, 2019.

Brogi, C., Huisman, J. A., Herbst, M., Weihermüller, L., Klosterhalfen, A., Montzka, C., Reichenau, T. G., and Vereecken, H.: Simulation of spatial variability in crop leaf area index and yield using agroecosystem modeling and geophysics-based quantitative soil information, Vadose Zone J., 19, e20009, https://doi.org/10.1002/vzj2.20009, 2020.

Busch, S., van der Kruk, J., and Vereecken, H.: Improved Characterization of Fine-Texture Soils Using On-Ground GPR FullWaveform Inversion, IEEE T. Geosci. Remote, 52, 3947-3958, https://doi.org/10.1109/TGRS.2013.2278297, 2014.

Della-Marta, P. M. and Wanner, H.: A Method of Homogenizing the Extremes and Mean of Daily Temperature Measurements, J. Clim., 19, 4179-4197, https://doi.org/10.1175/JCLI3855.1, 2006.

Dengel, S., Graf, A., Grünwald, T., Hehn, M., Kolari, P., Löfvenius, M. O., Merbold, L., Nicolini, G., and Pavelka, M.: Standardized precipitation measurements within ICOS: rain, snowfall and snow depth: a review, Int. Agrophys., 32, 607-617, https://doi.org/10.1515/intag-2017-0046, 2018.

Domonkos, P. and Coll, J.: Homogenisation of temperature and precipitation time series with ACMANT3: method description and efficiency tests: Homogenisation of time se- 
ries with ACMANT3, Int. J. Climatol., 37, 1910-1921, https://doi.org/10.1002/joc.4822, 2017.

Eder, F., Schmidt, M., Damian, T., Träumner, K., and Mauder, M.: Mesoscale Eddies Affect Near-Surface Turbulent Exchange: Evidence from Lidar and Tower Measurements, J. Appl. Meteorol. Climatol., 54, 189-206, https://doi.org/10.1175/JAMC-D14-0140.1, 2015.

Graf, A.: Gap-filling meteorological variables with Empirical Orthogonal Functions, Geophys. Res. Abstr.,no. 19, 2017.

Graf, A., Prolingheuer, N., Schickling, A., Schmidt, M., Schneider, K., Schüttemeyer, D., Herbst, M., Huisman, J. A., Weihermüller, L., Scharnagl, B., Steenpass, C., Harms, R., and Vereecken, H.: Temporal Downscaling of Soil Carbon Dioxide Efflux Measurements Based on Time-Stable Spatial Patterns, Vadose Zone J., 10, 239-251, https://doi.org/10.2136/vzj2009.0152, 2011.

Graf, A., Herbst, M., Weihermüller, L., Huisman, J. A., Prolingheuer, N., Bornemann, L., and Vereecken, H.: Analyzing spatiotemporal variability of heterotrophic soil respiration at the field scale using orthogonal functions, Geoderma, 181-182, 91101, https://doi.org/10.1016/j.geoderma.2012.02.016, 2012.

Heitmann-Weber, B., Mittelstaedt, W., and Fuhr, F.: The degradation of anilazine and dihydroxy-anilazine at various soil depths of an orthic luvisol, J. Environ. Sci. Health Pt. B, 29, 247-264, https://doi.org/10.1080/03601239409372878, 1994.

Hoffmeister, D., Waldhoff, G., Korres, W., Curdt, C., and Bareth, G.: Crop height variability detection in a single field by multitemporal terrestrial laser scanning, Precis. Agric., 17, 296-312, https://doi.org/10.1007/s11119-015-9420-y, 2016.

IUSS Working Group WRB: World Reference Base for Soil Resources 2014, FAO, Rome, Italy, 2015.

Jakobi, J., Huisman, J. A., Schrön, M., Fiedler, J., Brogi, C., Vereecken, H., and Bogena, H. R.: Error Estimation for Soil Moisture Measurements With Cosmic Ray Neutron Sensing and Implications for Rover Surveys, Front. Water, 2, 10, https://doi.org/10.3389/frwa.2020.00010, 2020.

Jones, J. W., Antle, J. M., Basso, B., Boote, K. J., Conant, R. T., Foster, I., Godfray, H. C. J., Herrero, M., Howitt, R. E., Janssen, S., Keating, B. A., Munoz-Carpena, R., Porter, C. H., Rosenzweig, C., and Wheeler, T. R.: Toward a new generation of agricultural system data, models, and knowledge products: State of agricultural systems science, Agric. Syst., 155, 269-288, https://doi.org/10.1016/j.agsy.2016.09.021, 2017.

Kalis, A. J.: Die menschliche Beeinflussung der Vegetationsverhältnisse auf der Aldenhovener Platte (Rheinland) während der vergangenen 2000 Jahre, in Archäologie in den rheinischen Lößbörden: Beiträge zur Siedlungsgeschichte im Rheinland, vol. 24, Rheinland-Verlag, Köln, 1983.

Kersebaum, K. C., Boote, K. J., Jorgenson, J. S., Nendel, C., Bindi, M., Frühauf, C., Gaiser, T., Hoogenboom, G., Kollas, C., Olesen, J. E., Rötter, R. P., Ruget, F., Thorburn, P. J., Trnka, M., and Wegehenkel, M.: Analysis and classification of data sets for calibration and validation of agroecosystem models, Environ. Model. Softw., 72, 402-417, https://doi.org/10.1016/j.envsoft.2015.05.009, 2015.

Klosterhalfen, A., Herbst, M., Weihermüller, L., Graf, A., Schmidt, M., Stadler, A., Schneider, K., Subke, J.-A., Huisman, J. A., and Vereecken, H.: Multi-site calibration and validation of a net ecosystem carbon exchange model for croplands, Ecol. Model.,
363, 137-156, https://doi.org/10.1016/j.ecolmodel.2017.07.028, 2017.

Korres, W., Koyama, C. N., Fiener, P., and Schneider, K.: Analysis of surface soil moisture patterns in agricultural landscapes using Empirical Orthogonal Functions, Hydrol. Earth Syst. Sci., 14, 751-764, https://doi.org/10.5194/hess-14-751-2010, 2010.

Korres, W., Reichenau, T. G., and Schneider, K.: Patterns and scaling properties of surface soil moisture in an agricultural landscape: An ecohydrological modeling study, J. Hydrol., 498, 89102, 2013.

Kuglitsch, F. G., Toreti, A., Xoplaki, E., Della-Marta, P. M., Luterbacher, J., and Wanner, H.: Homogenization of daily maximum temperature series in the Mediterranean, J. Geophys. Res., 114, D15108, https://doi.org/10.1029/2008JD011606, 2009.

Mauder, M. and Foken, T.: Documentation and Instruction Manual of the Eddy-Covariance Software Package TK3, Universität Bayreuth, Abt. Mikrometeorologie, Bayreuth, 2011.

Mauder, M., Cuntz, M., Drüe, C., Graf, A., Rebmann, C., Schmid, H. P., Schmidt, M., and Steinbrecher, R.: A strategy for quality and uncertainty assessment of long-term eddycovariance measurements, Agr. Forest Meteorol., 169, 122-135, https://doi.org/10.1016/j.agrformet.2012.09.006, 2013.

Meier, U., Bleiholder, H., Buhr, L., Feller, C., Hack, H., Heß, M., Lancashire, P. D., Schnock, U., Stauß, R., van den Boom, T., Weber, E., and Zwerger, P.: The BBCH system to coding the phenological growth stages of plants - history and publications, J. Cultiv. Plants, 61, 41-52, 2009.

Mestre, O., Gruber, C., Prieur, C., Caussinus, H., and Jourdain, S.: SPLIDHOM: A Method for Homogenization of Daily Temperature Observations, J. Appl. Meteorol. Climatol., 50, 2343-2358, https://doi.org/10.1175/2011JAMC2641.1, 2011.

Meyer, N., Bornemann, L., Welp, G., Schiedung, H., Herbst, M., and Amelung, W.: Carbon saturation drives spatial patterns of soil organic matter losses under long-term bare fallow, Geoderma, 306, 89-98, https://doi.org/10.1016/j.geoderma.2017.07.004, 2017.

Moore, C. J.: Frequency response corrections for eddy correlation systems, Bound.-Lay. Meteorol., 37, 17-35, https://doi.org/10.1007/BF00122754, 1986.

Nemes, A., Wosten, J. H. M., Lilly, A., and Voshaar, J. H. O.: Evaluation of different procedures to interpolate particle-size distributions to achieve compatibility within soil databases, Geoderma, 90, 187-202, 1999.

Ney, P. and Graf, A.: High-Resolution Vertical Profile Measurements for Carbon Dioxide and Water Vapour Concentrations Within and Above Crop Canopies, Bound.-Lay. Meteorol., 166, 449-473, https://doi.org/10.1007/s10546-017-0316-4, 2018.

Prolingheuer, N., Scharnagl, B., Graf, A., Vereecken, H., and Herbst, M.: On the spatial variation of soil rhizospheric and heterotrophic respiration in a winter wheat stand, Agr. Forest Meteorol., 195-196, 24-31, https://doi.org/10.1016/j.agrformet.2014.04.016, 2014.

Pütz, T.: Lysimeterversuche zum Verlagerungsverhalten von Methabenzthiazuron und gelöstem organischen Kohlenstoff in einer Parabraunerde, Aufbau von zwei Klimameßstationen und Untersuchungen zur Validierung des Lysimetersystems, Forschungszentrum Zentralbibliothek, Jülich, available at: http://gso.gbv.de/DB=2.1/PPNSET?PPN=152374191 (last access: 7 March 2019), 1993. 
R Core Team: R, R Foundation for Statistical Computing, Vienna, Austria, 2017.

Reichenau, T. G., Korres, W., Montzka, C., Fiener, P., Wilken, F., Stadler, A., Waldhoff, G., and Schneider, K.: Spatial Heterogeneity of Leaf Area Index (LAI) and Its Temporal Course on Arable Land: Combining Field Measurements, Remote Sensing and Simulation in a Comprehensive Data Analysis Approach (CDAA), PLOS ONE, 11, e0158451, https://doi.org/10.1371/journal.pone.0158451, 2016.

Reichenau, T. G., Korres, W., Schmidt, M., Graf, A., Welp, G., Meyer, N., Stadler, A., Brogi, C. and Schneider, K.: A comprehensive dataset of vegetation states, fluxes of matter and energy, weather, agricultural management, and soil properties from intensively monitored crop sites in Western Germany, https://doi.org/10.5880/TR32DB.39, 2020.

Sakai, T., Iizumi, T., Okada, M., Nishimori, M., Grünwald, T., Prueger, J., Cescatti, A., Korres, W., Schmidt, M., Carrara, A., Loubet, B., and Ceschia, E.: Varying applicability of four different satellite-derived soil moisture products to global gridded crop model evaluation, Int. J. Appl. Earth Obs. Geoinf., 48, 5160, https://doi.org/10.1016/j.jag.2015.09.011, 2016.

Schad, P., Krasilnikov, P. V., and Arnold, R.: German Soil Classification, in: A handbook of soil terminology, correlation and classification, edited by: Krasilnikov, P. V., Ibáñez Martí, J. J., Arnold, R., and Shoba, S., Earthscan, London, Sterling, VA, 122$130,2009$.

Schiedung, H., Bornemann, L., and Welp, G.: Seasonal Variability of Soil Organic Carbon Fractions Under Arable Land, Pedosphere, 27, 380-386, https://doi.org/10.1016/S10020160(17)60326-6, 2017.

Schmidt, M., Reichenau, T. G., Fiener, P., and Schneider, K.: The carbon budget of a winter wheat field: An eddy covariance analysis of seasonal and inter-annual variability, Agr. Forest Meteorol., 165, 114-126, https://doi.org/10.1016/j.agrformet.2012.05.012, 2012.

Schotanus, P., Nieuwstadt, F. T. M., and De Bruin, H. A. R.: Temperature measurement with a sonic anemometer and its application to heat and moisture fluxes, Bound.-Lay. Meteorol., 26, 81-93, https://doi.org/10.1007/BF00164332, 1983.

Schulz, E.: Influence of site conditions and management on different soil organic matter (som) pools, Arch. Agron. Soil Sci., 50, 33-47, https://doi.org/10.1080/03650340310001627577, 2004.

Simmer, C., Thiele-Eich, I., Masbou, M., Amelung, W., Bogena, H., Crewell, S., Diekkrüger, B., Ewert, F., Hendricks Franssen, H.-J., Huisman, J. A., Kemna, A., Klitzsch, N., Kollet, S., Langensiepen, M., Löhnert, U., Rahman, A. S. M. M., Rascher, U., Schneider, K., Schween, J., Shao, Y., Shrestha, P., Stiebler, M., Sulis, M., Vanderborght, J., Vereecken, H., van der Kruk, J., Waldhoff, G., and Zerenner, T.: Monitoring and Modeling the Terrestrial System from Pores to Catchments, B. Am. Meteorol. Soc., 96, 1765-1787, https://doi.org/10.1175/BAMS-D-1300134.1, 2015.
Trewin, B.: A daily homogenized temperature data set for Australia, Int. J. Climatol., 33, 1510-1529, https://doi.org/10.1002/joc.3530, 2013.

Van Dijk, A., Moene, A. F., and De Bruin, H. A. R.: The principles of surface flux physics: theory, practice and description of the ECPACK library, Meteorology and Air Quality Group, Wageningen University, Wageningen, the Netherlands, 2004.

Venema, V. K. C., Mestre, O., Aguilar, E., Auer, I., Guijarro, J. A., Domonkos, P., Vertacnik, G., Szentimrey, T., Stepanek, P., Zahradnicek, P., Viarre, J., Müller-Westermeier, G., Lakatos, M., Williams, C. N., Menne, M. J., Lindau, R., Rasol, D., Rustemeier, E., Kolokythas, K., Marinova, T., Andresen, L., Acquaotta, F., Fratianni, S., Cheval, S., Klancar, M., Brunetti, M., Gruber, C., Prohom Duran, M., Likso, T., Esteban, P., and Brandsma, T.: Benchmarking homogenization algorithms for monthly data, Clim. Past, 8, 89-115, https://doi.org/10.5194/cp8-89-2012, 2012.

Vereecken, H., Kollet, S., and Simmer, C.: Patterns in SoilVegetation-Atmosphere Systems: Monitoring, Modeling, and Data Assimilation, Vadose Zone J., 9, 821-827, https://doi.org/10.2136/vzj2010.0122, 2010.

Vincent, L. A., Zhang, X., Bonsal, B. R., and Hogg, W. D.: Homogenization of Daily Temperatures over Canada, J. Clim., 15, 1322-1334, https://doi.org/10.1175/15200442(2002)015<1322:HODTOC>2.0.CO;2, 2002.

von Hebel, C., Matveeva, M., Verweij, E., Rademske, P., Kaufmann, M. S., Brogi, C., Vereecken, H., Rascher, U., and van der Kruk, J.: Understanding Soil and Plant Interaction by Combining Ground-Based Quantitative Electromagnetic Induction and Airborne Hyperspectral Data, Geophys. Res. Lett., 45, 7571-7579, https://doi.org/10.1029/2018GL078658, 2018.

Webb, E. K., Pearman, G. I., and Leuning, R.: Correction of flux measurements for density effects due to heat and water vapour transfer, Q. J. Roy. Meteor. Soc., 106, 85-100, https://doi.org/10.1002/qj.49710644707, 1980.

Webster, R.: Regression and functional relations, Eur. J. Soil Sci., 48, 557-566, https://doi.org/10.1111/j.13652389.1997.tb00222.x, 1997.

Wieneke, S., Burkart, A., Cendrero-Mateo, M. P., Julitta, T., Rossini, M., Schickling, A., Schmidt, M., and Rascher, U.: Linking photosynthesis and sun-induced fluorescence at subdaily to seasonal scales, Remote Sens. Environ., 219, 247-258, https://doi.org/10.1016/j.rse.2018.10.019, 2018.

Wijngaard, J. B., Klein Tank, A. M. G., and Können, G. P.: Homogeneity of 20th century European daily temperature and precipitation series: Homogeneity of European Climate Series, Int. J. Climatol., 23, 679-692, https://doi.org/10.1002/joc.906, 2003.

Zeileis, A. and Grothendieck, G.: zoo: S3 Infrastructure for Regular and Irregular Time Series, J. Stat. Softw., 14, 6, https://doi.org/10.18637/jss.v014.i06, 2005. 